\title{
D2PC SENSITIVITY ANALYSIS
}

\author{
D. P. Lombardi
}

Date Published-August 1992

\author{
Prepared for the \\ U.S. DEPARTMENT OF THE ARMY \\ Office of the Assistant Secretary, \\ Installations, Logistics and Environment \\ Under Interagency Agreement DOE No. 1769-1354-A1 \\ and \\ FEDERAL EMERGENCY MANAGEMENT AGENCY \\ Office of Natural and Technological Hazards \\ Under Interagency Agrecment No. 1457-B16-A1
}

\author{
Prepared by the \\ OAK RIDGE NATIONAL LABORATORY \\ Oak Ridge, Tennessee 37831 \\ managed by \\ MARTIN MARIETTA ENERGY SYSTEMS, INC. \\ for the \\ U.S. DEPARTMENT OF ENERGY \\ under Contract No. DE-AC05-84OR21400
}




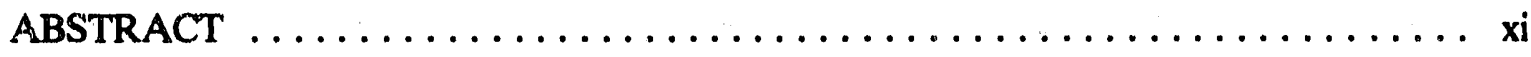

1. INTRODUCTION $\ldots \ldots \ldots \ldots \ldots \ldots \ldots \ldots \ldots \ldots \ldots \ldots \ldots \ldots \ldots \ldots \ldots \ldots, 1-1$

2. DESCRIPTION OF THE MODEL $\ldots \ldots \ldots \ldots \ldots \ldots \ldots \ldots \ldots \ldots \ldots \ldots \ldots \ldots \ldots, 2-1$

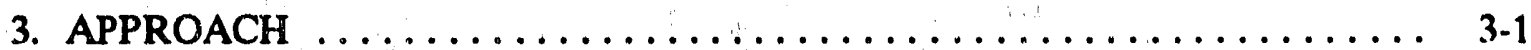

3.1 METEOROLOGICAL CATEGORIES $\ldots \ldots \ldots \ldots \ldots \ldots \ldots \ldots, \quad 3-1$

3.2 ACCIDENT SCENARIO DESCRIPTIONS $\ldots \ldots \ldots \ldots \ldots \ldots \ldots \ldots, \mathbf{3 - 1}$

3.3 RELEASE MODES $\ldots \ldots \ldots \ldots \ldots \ldots \ldots \ldots \ldots \ldots \ldots \ldots, 3-3$

4. SENSITIVITY ANALYSIS $\ldots \ldots \ldots \ldots \ldots \ldots \ldots \ldots \ldots \ldots \ldots, 4 . \ldots \ldots \ldots$

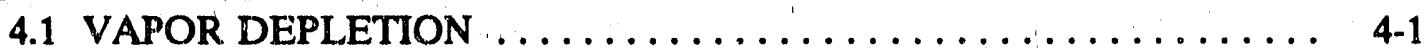

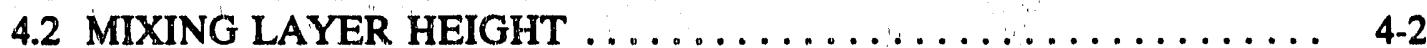

4.3 WIND SPEED BY STABILITY CLASS $\ldots \ldots \ldots \ldots \ldots \ldots \ldots \ldots, 4.6$

4.4 WIND PROFILE EXPONENT $\ldots \ldots \ldots \ldots \ldots \ldots \ldots \ldots \ldots \ldots, 4-10$

4.5 SURFACE ROUGHNESS HEIGHT $\ldots \ldots \ldots \ldots \ldots \ldots \ldots \ldots \ldots, 4-11$

4.6 EVAPORATIVE RELEASE VARIAB

4.7 INHALATION-DEPOSITION VARIABLES $\ldots \ldots \ldots \ldots \ldots \ldots \ldots .4 .19$

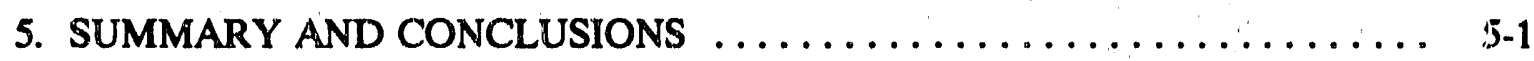

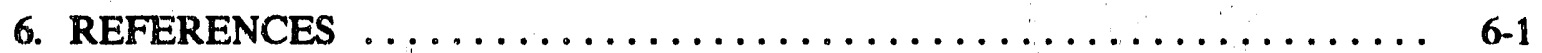




\section{LIST OF FIGURES}

Fig. 3.1. Flow chart representing the calculation of downwind distance

for a complex release mode-Scenario $2 \ldots \ldots \ldots \ldots \ldots \ldots \ldots \ldots$ 3-3

Fig. 4.1. Variable mixing height $(\mathrm{m})$-Scenario $1 \ldots \ldots \ldots \ldots \ldots \ldots \ldots \ldots \ldots$

Fig. 4.2. Variable mixing height $(\mathrm{m})$-Scenario $2 \ldots \ldots \ldots \ldots \ldots \ldots \ldots \ldots \ldots$

Fig. 4.3. Variable mixing height $(m)$-Scenario $3 \ldots \ldots \ldots \ldots \ldots \ldots \ldots \ldots \ldots$

Fig. 4.4. Variable mixing height $(\mathrm{m})$-Scenario $4 \ldots \ldots \ldots \ldots \ldots \ldots \ldots \ldots \ldots$

Fig. 4.5. Variable mixing height $(\mathrm{m})$-Scenario $5 \ldots \ldots \ldots \ldots \ldots \ldots \ldots \ldots$

Fig. 4.6. Variable mixing height $(\mathrm{m})$-Scenario $6 \ldots \ldots \ldots \ldots \ldots \ldots \ldots \ldots \ldots$

Fig. 4.7. Variable wind speed $(\mathrm{m} / \mathrm{s})$ by stability class-Scenario $1 \ldots \ldots \ldots \ldots$. $\ldots$.

Fig. 4.8. Variable wind speed $(\mathrm{m} / \mathrm{s})$ by stability class - Scenario $2 \ldots \ldots \ldots \ldots$. $\ldots$.7

Fig. 4.9. Variable wind speed $(\mathrm{m} / \mathrm{s})$ by stability class-Scenario $3 \ldots \ldots \ldots \ldots$. $\ldots .8$

Fig. 4.10. Variable wind speed $(\mathrm{m} / \mathrm{s})$ by stability class-Scenario $4 \ldots \ldots \ldots \ldots .4 .4$

Fig. 4.11. Variable wind speed $(\mathrm{m} / \mathrm{s})$ by stability class - Srenario $5 \ldots \ldots \ldots \ldots$

Fig. 4.12. Variable wind speed $(\mathrm{m} / \mathrm{s})$ by stability class-Scenario $6 \ldots \ldots \ldots \ldots$. . . . .

Fig. 4.13. Variable wind profile exponent by stability class-Scenario $1 \ldots \ldots$. . . 4-12

Fig. 4.14. Variable wind profile exponent by stability class-Scenario $2 \ldots \ldots$. . 4-12

Fig. 4.15. Variable wind profile exponent by stability class-Scenario $3 \ldots \ldots$. . . 4-13

Fig. 4.16. Variable wind profile exponent by stability class-Scenario $4 \ldots \ldots \ldots$ 4-13

Fig. 4.17. Variable wind profile exponent by stability class-Scenario $5 \ldots \ldots \ldots$ 4-14

Fig. 4.18. Variable wind profile exponent by stability class-Scenario $6 \ldots \ldots$. . . 4-14

Fig. 4.19. Variable roughness height $(\mathrm{cm})$-Scenario $1 \ldots \ldots \ldots \ldots \ldots \ldots \ldots$ 4-16

Fig. 4.20. Variable roughness height $(\mathrm{cm})$-Scenario $2 \ldots \ldots \ldots \ldots \ldots \ldots \ldots \ldots$. . . . . . . .

Fig. 4.21. Variable roughness height $(\mathrm{cm})$-Scenario $3 \ldots \ldots \ldots \ldots \ldots \ldots \ldots$. . . . . . . . . . .

Fig. 4.22. Variable roughness height $(\mathrm{cm})$-Scenario $4 \ldots \ldots \ldots \ldots \ldots \ldots \ldots$ 4-17

Fig. 4.23. Variable roughness height $(\mathrm{cm})$-Scenario $5 \ldots \ldots \ldots \ldots \ldots \ldots \ldots$ 4-18

Fig. 4.24. Variable roughness height $(\mathrm{cm})$-Scenario $6 \ldots \ldots \ldots \ldots \ldots \ldots \ldots$ 4-18

Fig. 4.25. Variable temperature $\left({ }^{\circ} \mathrm{C}\right)$-Scenario $3 \ldots \ldots \ldots \ldots \ldots \ldots \ldots \ldots \ldots$ 4-20

Fig. 4.26. Variable surface pressure $(\mathrm{mm} \mathrm{Hg})$-Scenario $3 \ldots \ldots \ldots \ldots \ldots \ldots$ 4-20

Fig. 4.27. Variable breathing rate (liters/min)-Scenario $1 \ldots \ldots \ldots \ldots \ldots \ldots$ 4-22

Fig. 4.28. Variable breathing rate (liters/min)-Scenario $2 \ldots \ldots \ldots \ldots \ldots \ldots \ldots$ 4-22

Fig. 4.29. Variable breathing rate (liters/min)-Scenario $3 \ldots \ldots \ldots \ldots \ldots \ldots$. . $\ldots \ldots$

Fig. 4.30. Variable breathing rate (liters/min)-Scenario $4 \ldots \ldots \ldots \ldots \ldots \ldots$ 4-23

Fig. 4.31. Variable breathing rate (liters $/ \mathrm{min})$-Scenario $5 \ldots \ldots \ldots \ldots \ldots \ldots$ 4-24

Fig. 4.32. Variable breathing rate (liters/min)-Scenario $6 \ldots \ldots \ldots \ldots \ldots \ldots$. . . . . . .

Fig. 4.33. Variable skin penetration factor-Scenario $1 \ldots \ldots \ldots \ldots \ldots \ldots \ldots$ 4-26

Fig. 4.34. Variable skin penetration factor-Scenario $2 \ldots \ldots \ldots \ldots \ldots \ldots$ 4-26 


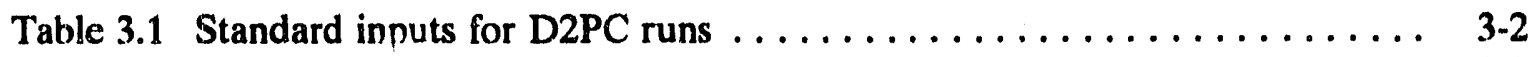

Table 3.2 Input parameters by accident scenario $\ldots \ldots \ldots \ldots \ldots \ldots \ldots \ldots \ldots$

Table 4.1 Comparison of downwind distances with and without vapor depletion mode for conservative most likely meteorological

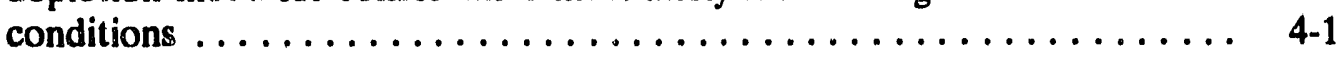

Table 4.2 Comparison of downwind distances with and without vapor depletion mode for worst case meteorological conditions . . . . . . . 4-2

Table 4.3 Wind speed ranges used for each stability class $\ldots \ldots \ldots \ldots \ldots \ldots \ldots$. . . . . .

Table 4.4 Frost wind profile exponent number ranges for each stability class . . . . 4 4-10

Table 4.5 Surface roughness heights with corresponding surface features . . . . . 4-15

Table 4.6 Selected breathing rates and corresponding activity levels . . . . . . 4-21

Table 5.1 Qualitative sensitivity ranking of parameters $\ldots \ldots \ldots \ldots \ldots \ldots \ldots .2$ 


\section{ABBREVIATIONS AND ACRONYMS}

AChE

cm

CML

CRDEC

CSDP

CSEPP

D2PC

EPA

EVP

FPEIS

$\mathrm{ft}$

GB

HD

$\mathrm{Hg}$

INS

$\mathrm{km}$

m

$\mathrm{m} / \mathrm{s}$

$\mathrm{mg}$

min

SEM

STB

VDP

VX

WC acetylcholinesterase

centimeter

conservative most likely

Chemical Research Development and Engineering Center (U.S. Army)

Chemical Stockpile Disposal Program

Chemical Stockpile Emergency Preparedness Program

Personal Computer Program for Chemical Hazard

Prediction

U.S. Environmental Protection Agency

evaporative agent release

Final Programmatic Environmental Impact Statement

feet

organophosphate (nerve) agent; methylphosphonofluoridate, isopropyi-ester; $\mathrm{C}_{4} \mathrm{H}_{10} \mathrm{FO}_{2} \mathrm{P}$

vesicant (blister) agent; also called sulfur mustard; $\underline{\text { bis(2- }}$ chloroethyl) sulfide; $\mathrm{C}_{4} \mathrm{H}_{8} \mathrm{Cl}_{2} \mathrm{~S}$

mercury

instantaneous agent release

kilometer

meter

meters per se:ond

milligram

minute

semi-continuous agent release

stability (atmospheric)

vapor depletion module

organophosphate (nerve) agent; S-(diisopropyl aminoethyl) methylphospho-nothiolate, 0-ethylester; $\mathrm{C}_{11} \mathrm{H}_{26} \mathrm{NO}_{2} \mathrm{PS}$ worst case 


\section{ACKNOWLEDGEMENTS}

During the course of this research, a number of people have made contributions that have shaped its final outcome. The author sincerely appreciates the efforts of all who provided assistance, while accepting complete responsibility for the contents of this report.

Mike Myirski of the U.S. Army Chemical Research and Development Engineering Center provided invaluable information regarding the history, theory, and operation of D2PC.

Robert Miller was instrumental in developing the overall strategy for the analysis. His previous work with D2PC provided an important information resource.

Annetta Watson provided detailed guidance in the discussion of chemical warfare agents. Her help in constructing reasonable conclusions from the gathered data was extremely useful.

G. L. Chen was instrumental in dissecting D2PC. He discovered an error in the D2PC code regarding the inhalation-deposition algorithm that has since been verified and corrected.

Phil Wolff, Leigh Ann Daniel, and Lori Warneke were critical in the assembly and presentation of this document. 


\title{
D2PC SENSITTVITY ANALYSIS
}

by

\author{
D. P. LOMBARDI
}

\begin{abstract}
The Chemical Hazard Prediction Model (D2PC) developed by the U.S. Army will play a critical role in the Chemical Stockpile Emergency Preparedness Program by predicting chemical agent transport and dispersion through the atmosphere after an accidental release. To aid in the analysis of the output calculated by D2PC, this sensitivity analysis was conducted to provide information on model response to a variety of input parameters. The sensitivity analysis focused on six accidental release scenarios involving chemical agents VX, GB, and HD (sulfur mustard). Two categories, corresponding to conservative most likely and worst case meteorological conditions, provided the reference for standard input values. D2PC displayed a wide variety of sensitivity to the various input parameters. The model displayed the greatest overall sensitivity to wind speed, mixing height, and breathing rate. For other input parameters, sensiivity was mixed but generally lower. Sensitivity varied not only with parameter, but also over the range of values input for a single parameter. This information on model response can provide useful data for interpreting D2PC output.
\end{abstract}




\section{INTRODUCTION}

A vital component of the Chemical Stockpile Emergency Preparedness Program (CSEPP) is assessing the impacts of an accidental release of chemical agent. An important factor in this assessment is determining the dosage of agent (the multiplicative product of agent concentration and duration of exposure) received downwind of the accidental release. After release, chemical agent is transported and dispersed through the atmosphere in the form of vapor, aerosols, and droplets. One method for determining the agent's transport and dispersion involves the use of computer models. A model being considered for CSEPP use is the Personal Computer Program for Chemical Hazard Prediction (D2PC), developed by the U.S. Army Chemical Research and Development Center (Whiteacre et al. 1987). This report documents the sensitivity of D2PC model output to various input parameters. The exact value of a certain input parameter may not be known at the time of an accidental release. If the model is not sensitive to this parameter, then model output will not be greatly affected. However, if the model is sensitive to this parameter, then model output will be influenced by parameter uncertainty. Since D2PC output can be used by emergency planners to make critical decisions regarding fatality estimates, evacuation procedures, and area reentry, information regarding model sensitivity is necessary to enhance the decision-making process when considering these factors. 


\section{DESCRIPTION OF THE MODEL}

D2PC is an air dispersion model that assumes a Gaussian distribution of agent in the vertical and cross-wind direction as the agent disperses downwind. The development of Gaussian models has been documented extensively in the literature (Sutton 1932, Gifford 1968, Pasquill 1974), and many models currently use Gaussian distribution (EPA 1986). D2PC predicts dosage of agent expected at locations downwind of the release. The dosage used in this study corresponds to the minimum downwind distance where the simulated fatality rate of healthy adults is $0 \%$, otherwise known as the downwind distance to "no deaths."

The downwind distances used in the analysis are for locations along the center of the plume or cloud of agent as it travels downwind. Dosages of agent are greater along this "centerline" than to either side and are predicted by D2PC to decrease from the centerline according to a Gaussian distribution. Thus, a given dosage is attained at a maximum distance along the centerline and is also found at shorter distances on either side of the centerline (Miller and Kornegay 1989).

The greatest advantage of D2PC is that detailed information on the type of chemical warfare agent accident to be modeled is incorporated in the model's code. Input parameters include type of agent, mode of release, and duration of release. The model also takes into account the ability of the human body to metabolize certain nerve agents by incorporating a correction for the length of exposure, termed the "two-minute factor." It has been shown that the dosage of GB or VX vapor required to produce a given physiological effect is dependent on the time of accumulation. Thus, the total dosage is not an adequate index for long exposures (i.e., $>2$ minutes). Since the time of exposure is dependent on the size of the vapor plume, a correction was developed in D2PC that converts the accumulated dosage at any point to the equivalent 2-minute dosage (Whiteacre et al. 1987, p. 90). This factor prevents overestimation of impacts from a very long exposure to very low concentrations. The model is a flat terrain model, which generally provides conservative estiniates (i.e. overestimates) for ground-level releases because no credit is taken for the potential movement of the plume around terrain features. Additionally, the D2PC assumption of straight-line transport with nonvarying meteorological conditions results in conservative estimates of the effects of releases (actual effects should be less). 


\section{APPROACH}

To examine the sensitivity of D2PC, perturbation of one variable at a time was considered sufficient for cho acterizing the sensitivity of the model. Parameters were input to the model to describe the nature of the chemical agent release and the meteorological conditions at the time of the release. The parameters examined were mixing layer height, win'ı speed, wind speed profile, atmospheric stability, surface roughness, breathing rate, skin penetration factor, temperature, and atmospheric pressure. Some input parameters are dependent on others, especially when the range in which a parameter can vary is determined by another variable (e.g., wind speed range is limited by atmospheric stability). Additionally, sensitivity was examined under two specific meteorological categories that further limit parameter value but will enhance understanding of model behavior under characteristic meteorological conditions. With these constraints included, it was then possible to vary particular parameters while holding all others constant. Downwind "no deaths" distances were calculated over a specific range of a parameter, and sensitivity was determined by examining the change in downwind distance over this range.

\subsection{METEOROLOGICAL CATEGORIES}

Baseline input meteorological parameters are broken into two categories, worst case (WC) and conservative most likely (CML). Table 3.1 lists the input parameters for both cases, with the parameters listed in the left column and the input values for each condition listed in the middle and right columns. Worst case meteorological conditions were chosen for accident release assessments in the Final Programmatic Environmental Impact Statement (FPEIS) for the U.S. Army's Chemical Stockpile Disposal Program (CSDP) to obtain the upper bound estimates of public health impacts (U.S. Dept. of the Army 1988). The worst case is a credible meteorological condition that results in near-maximum drises. Conservative most likely conditions are frequently occurring meteorological conditions that result in relatively larger doses of agent compared with other frequently occurring conditions.

\section{ACCIDENT SCENARIO DESCRIPTIONS}

This sensitivity analysis examined six accident scenarios. Scenario-specific D2PC model input is shown in Table 3.2. All scenario-specific inputs were held constant within each sensitivity run, and the sensitivity of these accident-related parameters was not determined. Three chemical agents were considered: VX, GB, and HD. VX and GB are organophosphate (nerve) agents that inhibit the functioning of the enzyme acetylcholinesterase (AChE), causing dysfunction of the nervous system. HD (also called sulfur mustard) is a vesicant (blister) agent that causes damage to cells it contacts, producing eye and respiratory tract irritation, blisters, skin rashes and other effects (Munro et al. 1990).

Scenario 1 represents the dropping and subsequent detonation of a pallet loaded with VX munitions between the munitions handling igloo and military demilitarization building. Scenario 2 represents a vehicle carrying VX munitions being involved in an accident in which a fire causes the detonation of burstered munitions. Scenarios 3 and 4 are somewhat similar to scenarios 1 and 2, respectively, except GB is the released agent. 
Table 3.1. Standard inputs for D2PC runs

\begin{tabular}{|c|c|c|}
\hline D2PC input code & Worst case & $\begin{array}{c}\text { Conservative most } \\
\text { likely }\end{array}$ \\
\hline Stability Class (STB) ${ }^{a}$ & $\mathbf{E}$ & D \\
\hline Wind Speed $(\mathrm{m} / \mathrm{s})(\mathrm{WND})$ & 1 & 3 \\
\hline Temperature $\left({ }^{\circ} \mathrm{C}\right)(\mathrm{TMP})$ & 30 & 20 \\
\hline Surface Pressure (mm Hg) (PMM) & 760 & 760 \\
\hline Mixing Layer Height (m) (HML) & 750 & 750 \\
\hline Vapor Depletion Code (VDP) & 1 & 1 \\
\hline Frost (Wind Profile) Exponent Number (FRO) & 0.25 & 0.25 \\
\hline Roughness Height $(\mathrm{cm})(\mathrm{ZZO})$ & 1 & 1 \\
\hline Breathing Rate (liters/min) (BRT) & 25 & 25 \\
\hline Skin Penetration Factor (SKF) & 0.022 & 0.022 \\
\hline Evaporative Surface Code (SUR) & $\mathrm{NPR}^{b}$ & NPR \\
\hline Munition Code (MUN) & NON ${ }^{c}$ & NON \\
\hline Location Code (LOC) & $\mathrm{NDF}^{d}$ & NDF \\
\hline
\end{tabular}

Table 3.2. Input parameters by accident scenario

\begin{tabular}{lcccccc}
\hline Scenario number & 1 & 2 & 3 & 4 & 5 & 6 \\
Scenario ID & HF11 & VO4 & HF11 & VO4 & HF3 & HO2 \\
Agent released & VX & VX & GB & GB & VX & HD \\
& & \multicolumn{5}{c}{ Amount released } \\
INS (mg) & $1.4 \mathrm{E} 07$ & $1.7 \mathrm{E} 08$ & $9.7 \mathrm{E} 06$ & $2.4 \mathrm{E} 07$ & 0 & 0 \\
SEM (mg) & 0 & $2.0 \mathrm{E} 08$ & 0 & $1.2 \mathrm{E} 08$ & $1.8 \mathrm{E} 07$ & $3.9 \mathrm{E} 07$ \\
EVP (mg) & 0 & $2.7 \mathrm{E} 05$ & $1.4 \mathrm{E} 07$ & $1.5 \mathrm{E} 05$ & 0 & 0 \\
Event duration (min) & 60 & 20 & 60 & 20 & 10 & 10 \\
\hline
\end{tabular}

"Source: U.S. Department of the Army 1987. Risk Analysis in Support of the Chemical Stockpile Disposal Pragram: Consequence Dasa, SAPEO-CDE-87014, Program Executtve Office, Program Manager for Chemical Demilitarization, Aberdeen Proving Ground, Md.

${ }^{b} \mathrm{INS}=$ instantaneous release; $\mathrm{SEM}=$ semi-continuous releasc; $\mathrm{EVP}=$ evaporative release. 
Scenario 5 represents a forklift collision accident with a short duration fire during handling between the munitions handling igloo and the military demilitarization building. Finally, scenario 6 represents a forklift collision with a short duration fire at the storage area involving mustard munitions. These scenarios were selected because they are common to all eight chemical weapons demilitarization sites and have a higher probability of occurrence than other accidents.

\subsection{RELEASE MODES}

In D2PC, the agent release mode may be specified as instantaneous, semicontinuous, or evaporative. An instanianeous release corresponds to exploding munitions releasing agent mainly in the form of aerosols. A semi-continuous release corresponds to fire in which the agent is released in the form of vapor. An evaporative release corresponds to an agent spill in which the agent evaporates. A simple release involves only one of these modes. Scenarios 1,5 , and 6 are simple releases. Scenarios 2, 3, and 4 are complex releases, involving two or more modes. A method was developed to determine downwind distance involving a complex release by the MITRE Corporation for their accidental release assessment in the CSDP FPEIS (B. Cutler, MITRE Corporation, personal communication with D. P. Lombardi, ORNL, March 9, 1992). This method is illustrated in Fig. 3.1. For each scenario, there is a dominant form of release, while the other releases involved in the scenario are subordinate. To transform the subordinate release mode(s) to the dominant release mode, it is necessary to calculate the downwind distance generated by the subordinate release alone. Then the amount of agent required to generate this downwind distance in the dominant release mode is back-calculated. This amount is added to the original amount of agent released in the dominant mode, and a total effective amount is obtained to use with the dominant mode alone. This process can be repeated for additional modes of release. The total amount of agent thus calculated is used to determine the downwind distance of the complex release.

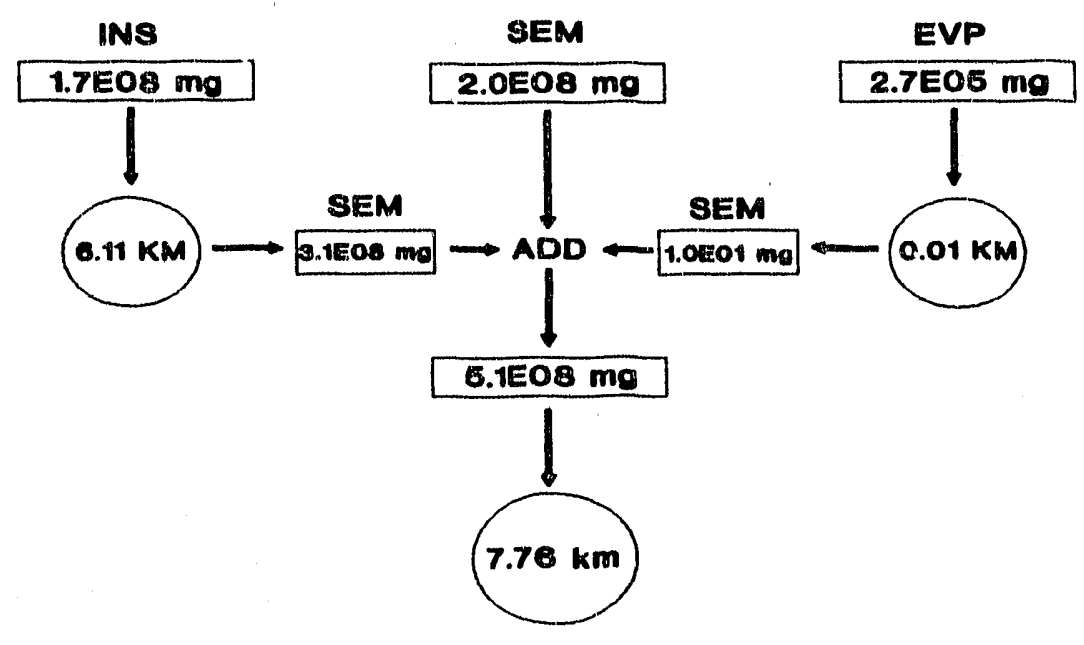

Fig. 3.1. Flow chart representing the calculation of downwind distance for a complex release mode-Scenario 2 


\section{SENSITTVITY ANALYSIS}

\subsection{VAFOR DEPLETION}

D2PC allows for input of a vapor depletion module, which takes into account the time-dependent deposition of the chemical agent upon many kinds of surfaces and employs an empirical source depletion method to model this effect (Whiteacre et al. 1987, p. 75). This empirical model calculates a dosage area and an effective deposition velocity, based upon wind profile, friction velocity, and surface roughness length, to determine the new effective source strength.

Vapor depletion is activated by setting the input parameter VDP to 1. Setting VDP to 0 (the default value) indicates that the downwind distance will be calculated without vapor depletion. Tables 4.1 and 4.2 show the downwind distance calculations for all six accident scenarios for both CML and WC meteorological conditions, respertively. Column four in both tebles shows the percent change in downwind distance when vapor depletion is calculated. For CML meteorological conditions, vapor depletion results in about a $24 \%-41 \%$ reduction in the downwind distance for scenarios 2 through 6 . Sicenario 1 has a reduction of only about $5 \%$ when vapor depletion is calculated. Only $10 \%$ of the vapor is depleted in scenario 1 by the time the plume reaches the downwind "no deaths" distance, while about $50 \%$ of the vapor is depleted in scenarios 2 through 5 by the time the plume reaches the downwind "no deaths" distance. Scenario 1 motels an instantaneous release of VX in which 87\% of the agent is transported thrcugh the air in the form of aerosols. Therefore, little vapor is available for depletion. For WC meteorological conditions, the percentage reductions in downwind distance due to vapor depletion are about half the corresponding percentage reductions for $\mathrm{CMl}$, conditions (about 13\%-22\% for scenarios 2 through 6 and about 2\% for scenario 1). This half reduction is caused by the generalized stability parameter used to calculate the surface

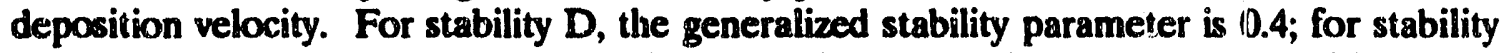
E the generalized stability parameter is 0.2 (Whiteacre et al. 1987, p. 76). In this instance, D2PC calculates a lower surface deposition velocity when atmospheric turbulence decreases.

Table 4.1. Comparieon of downwind distances with and without vapor depletion mode for conservative moat likely meteorological conditions"

\begin{tabular}{cccc}
\hline Scenario & $\begin{array}{c}\text { Downwind "no deaths" } \\
\text { distance (km), without } \\
\text { vapor depletion }\end{array}$ & $\begin{array}{c}\text { Downwind "no deaths" } \\
\text { distance (km), with } \\
\text { vapor depletion }\end{array}$ & $\begin{array}{c}\text { Percent } \\
\text { changfe }\end{array}$ \\
\hline 1 & 0.39 & 0.37 & -5.1 \\
2 & 10.12 & 6.02 & -40.5 \\
3 & 1.81 & 1.31 & -27.6 \\
4 & 4.78 & 3.04 & -36.4 \\
5 & 2.38 & 1.69 & -29.0 \\
6 & 0.54 & 0.41 & -24.1 \\
\hline
\end{tabular}

-Wind $=3.0 \mathrm{~m} / \mathrm{s}$ and stability $=D$. 
Table 4.2 Comparison of downwind distances with and without vapor depletion mode for worst case meteorological conditionsa

\begin{tabular}{cccc}
\hline Scenario & $\begin{array}{c}\text { Downwind distance }(\mathrm{km}), \\
\text { without vapor depletion }\end{array}$ & $\begin{array}{c}\text { Downwind distance }(\mathrm{km}), \\
\text { with vapor depletion }\end{array}$ & $\begin{array}{c}\text { Percent } \\
\text { change }\end{array}$ \\
\hline 1 & 0.49 & 0.48 & -2.0 \\
2 & 32.16 & 25.09 & -22.0 \\
3 & 4.90 & 4.23 & -13.7 \\
4 & 14.90 & 12.06 & -19.1 \\
5 & 7.14 & 6.08 & -14.8 \\
6 & 1.74 & 1.52 & -12.6 \\
\hline
\end{tabular}

$\bullet$ Wind $=1.0 \mathrm{~m} / \mathrm{s}$ and stability $=\mathrm{E}$.

\subsection{MIXING LAYER HEIGHT}

The mixing layer height is the height above the surface to the top of a layer in which mixing by turbulence tends to approach uniformity. If the agent plume travels for sufficient distance, the vertical distribution becomes uniform within this layer. The height of the mixing layer is roughly inversely proportional to the dosage received at a particular downwind distance. Figures 4.1-4.6 show, for each accident scenario respectively, the downwind "no deathis" distance as a function of mixing heights under both WC and CML meteorological conditions. Mixing layer height is meaningless for WC conditions because there is no mixing layer in a stable atmosphere; however, D2PC requires a mixing height value for all downwind distance calculations regardless of the stability class. Therefore, variable mixing height was analyzed for WC conditions.

The roughly inverse relationship is apparent within each plot; however, there is a certain point that downwind distances remain the same for subsequent increases in mixing height. This is the minimum achievable downwind distance for the specified set of input parameters. At this point, vertical dispersion of the plume is not constrained by the inversion layer that limits dispersion immediately above the mixed layer. This minimum achievable downwind distance occurs for all scenarios well below the $750 \mathrm{~m}$ mixing height used in the accidental release assessment for the CSDP FPEIS. The model sensitivity is therefore only significant with low mixing height values. To examine sensitivity, calculations for all scenarios began with an extremely low mixing height of $10 \mathrm{~m}$. Mixing height was increased until the minimum achievable downwind distance was reached. If release amounts had been greater, the minimum achievable downwind distance may have occurred at a mixing height greater than $750 \mathrm{~m}$.

Scenario 5 shows an increase in downwind distance with increased mixing height for WC conditions. This occurs between mixing heights of 10 and $20 \mathrm{~m}$. This suspect output indicates that D2PC is not accurately computing the downwind distance with this extremely low mixing layer height. 


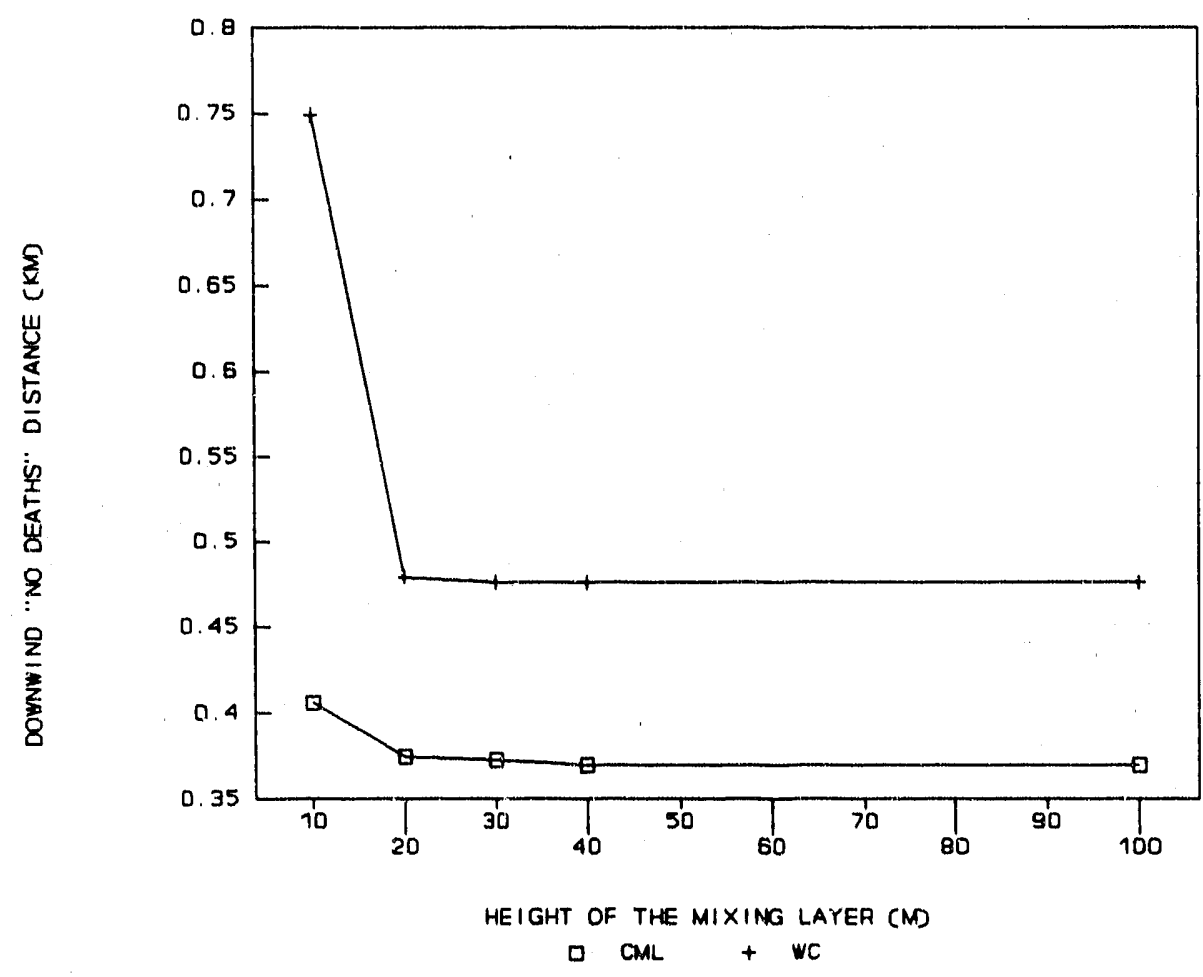

Fig. 4.1. Variable mixing height (m)-Scenario 1.

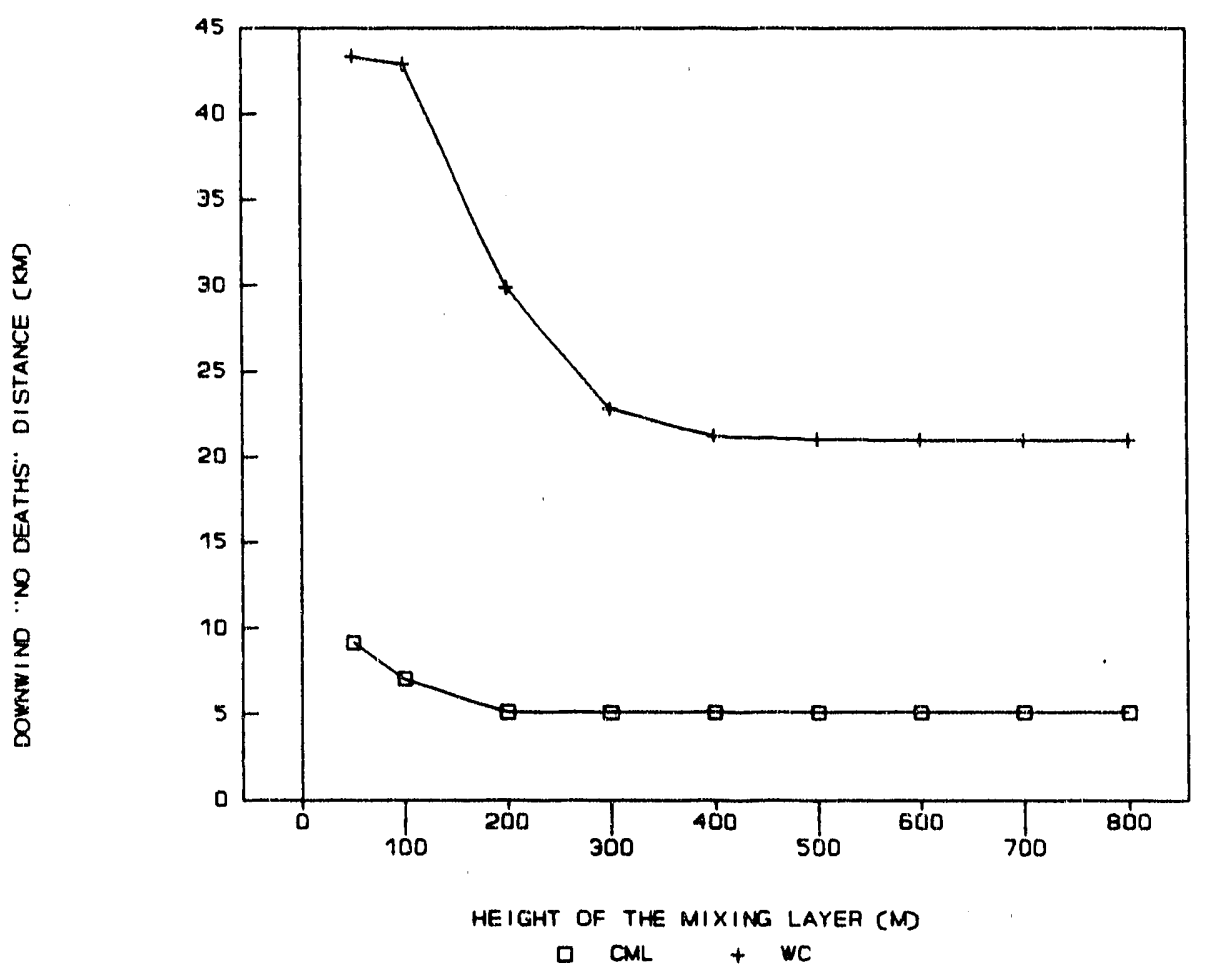

Fig. 4.2 Variable mixing height (m)-Scenario 2. 


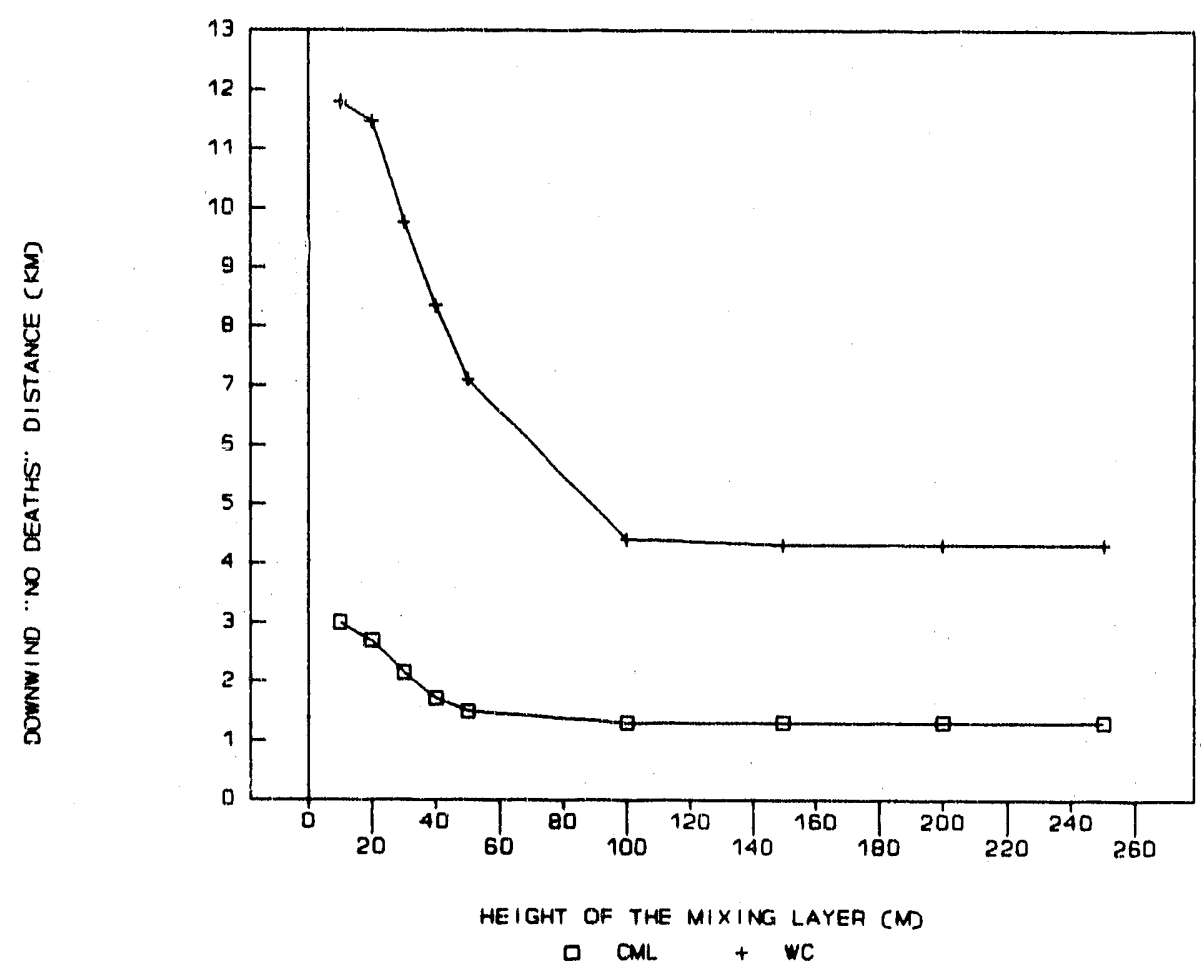

Fig 43. Variable mixing height (m)-Scenario 3.

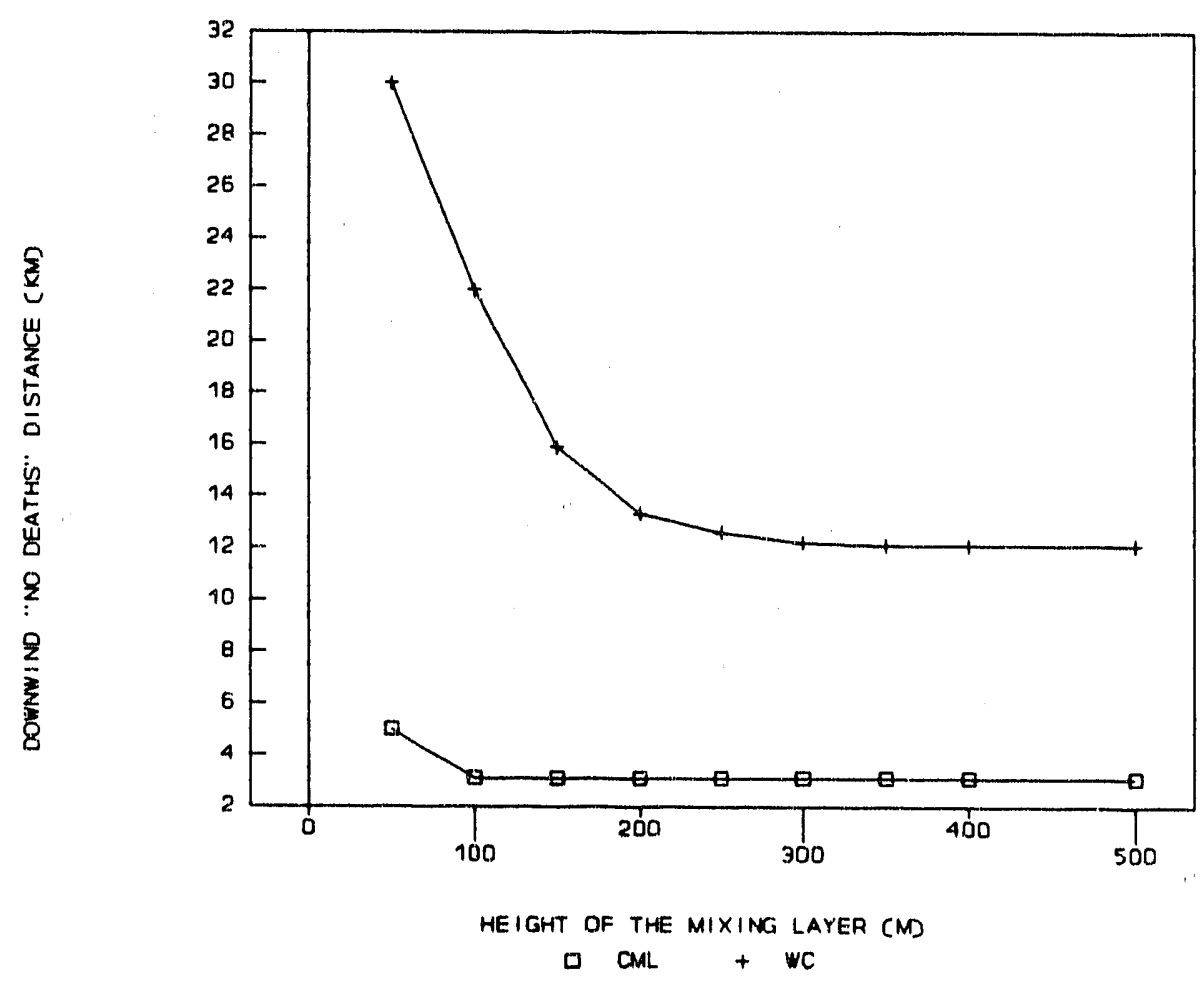

Fig. 4.4. Variable mixing height (m)-Scenario 4. 


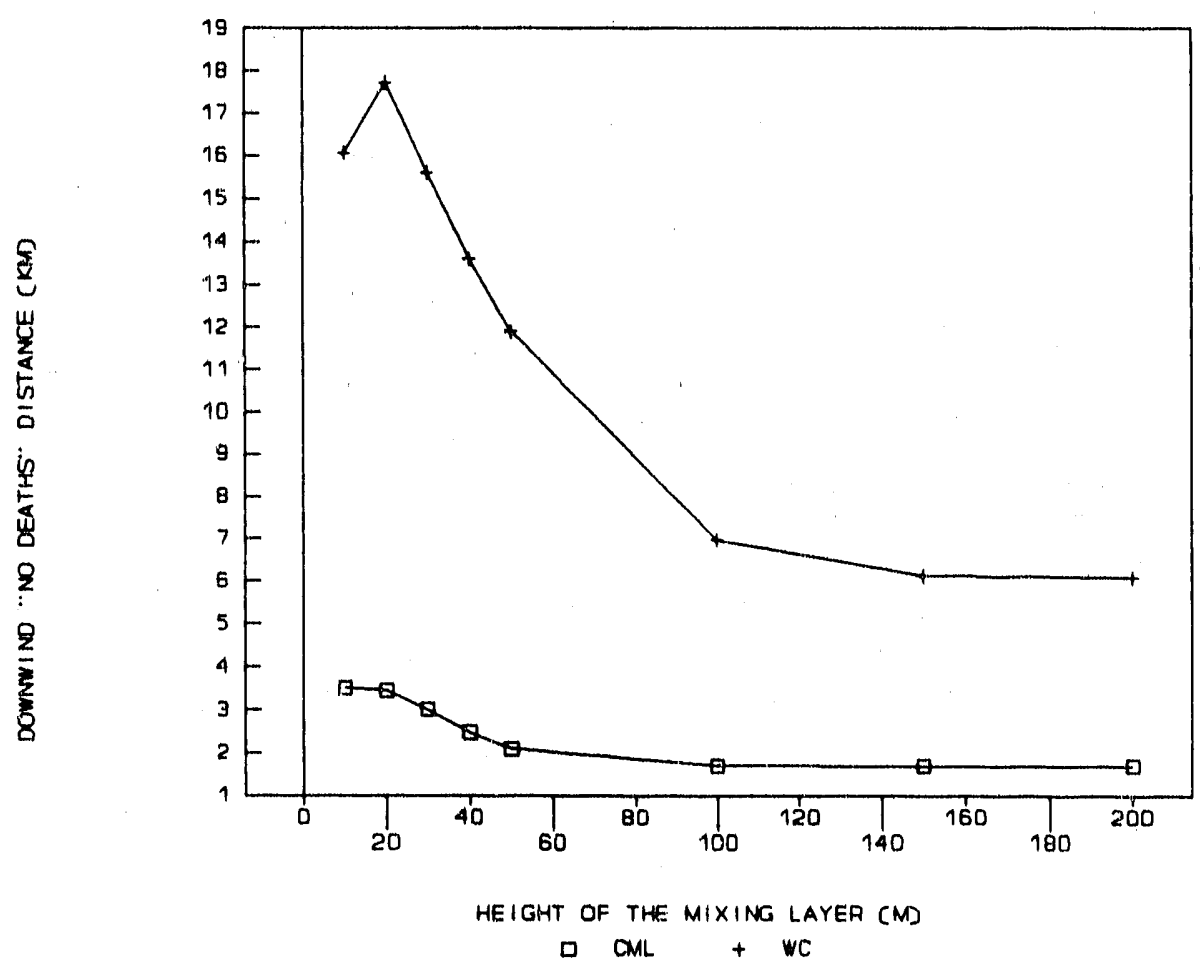

Fig. 4.5. Variable mixing height (m)-Scenario 5.

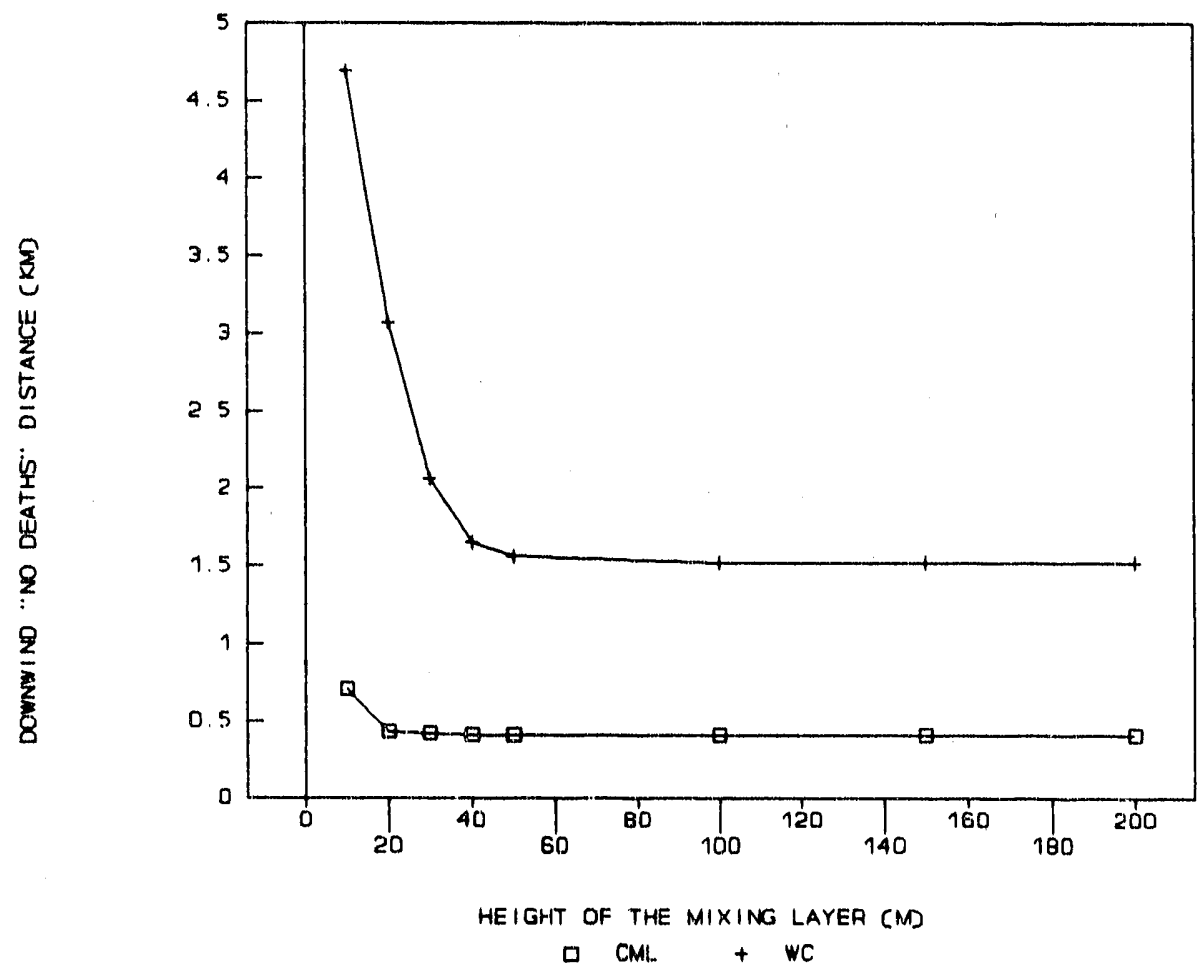

Fig. 4.6. Variable mixing height (m)-Scenario 6. 


\subsection{WIND SPEED BY STABUITY CLASS}

In a classical Gaussian air dispersion model, the dose received at a particular downwind distance is roughly inversely proportional to the wind speed. Wind speed range is limited within particular atmospheric stability classes, which fall into six different categories, A through F. Atmospheric stability is a function of the vertical temperature gradient. The atmosphere is stable when the temperature decreases slowly or increases with height. The atmosphere is unstable when temperature decreases rapidly with height (Pasquill 1961). For unstable conditions, large vertical eddies are created by thermal effects. As wind speed increases, these large vertical eddies decrease, mixing decreases, and stability increases. For stable conditions, the flow is somewhat laminar. As the wind speed increases, mechanical turbulence increases, mixing increases, and stability decreases. 'Therefore, stability class $D$ (neutral) has the largest range of wind speeds. Table 4.3 shows the wind speed ranges for each stability class used in this sensitivity analysis.

Temperature was set at $25^{\circ} \mathrm{C}$ since $\mathrm{CML}$ and WC meteorological conditions were not applied to this analysis. Figures 4.7-4.12, corresponding to accident scenarios 1 through 6 respectively, show the relationship between wind speed and downwind distance by stability class.

For scenarios 3 through 6 (Figs. 4.9-4.12), the downwind distance decreases with increasing wind speeds. Additionally, greater downwind distances are shown for more stable conditions. Sensitivity to wind speed is greatest for stable atmospheric conditions (stability classes $E$ and $F$ ) and for all stability classes between 1 and 2 meters per second. Stability class $A$ indicates a very unstable atmosphere, and for all scenarios, the agent dispersed very quickly with a downwind "no deaths" distance less than $10 \mathrm{~m}$.

For scenarios 1 and 2 (Figs. 4.7 and 4.8), the downwind distance initially decreases with increasing wind speed, but at a certain point, the downwind distance increases with increasing wind speed (this is true for all stability classes except $F$, where the inflection point is not reached due to wind speed limitations for this stability class). For explosive (instantaneous) releases of VX, dose is received both by respiratory and percutaneous routes, and when hazard distances are estimated, the percutaneous effect (which increases

Table 4.3. Wind speed ranges used for each stability class

\begin{tabular}{lc}
\hline \multicolumn{1}{c}{ Stability class } & $\begin{array}{c}\text { Wind speed range } \\
(\mathrm{m} / \mathrm{s})\end{array}$ \\
\hline A - very unstable & $1-4$ \\
B - unstable & $1-6$ \\
C - slightly unstable & $1-10$ \\
D - neutral & $1-20$ \\
E - slightly stable & $1-6$ \\
F - stable & $1-4$ \\
\hline
\end{tabular}




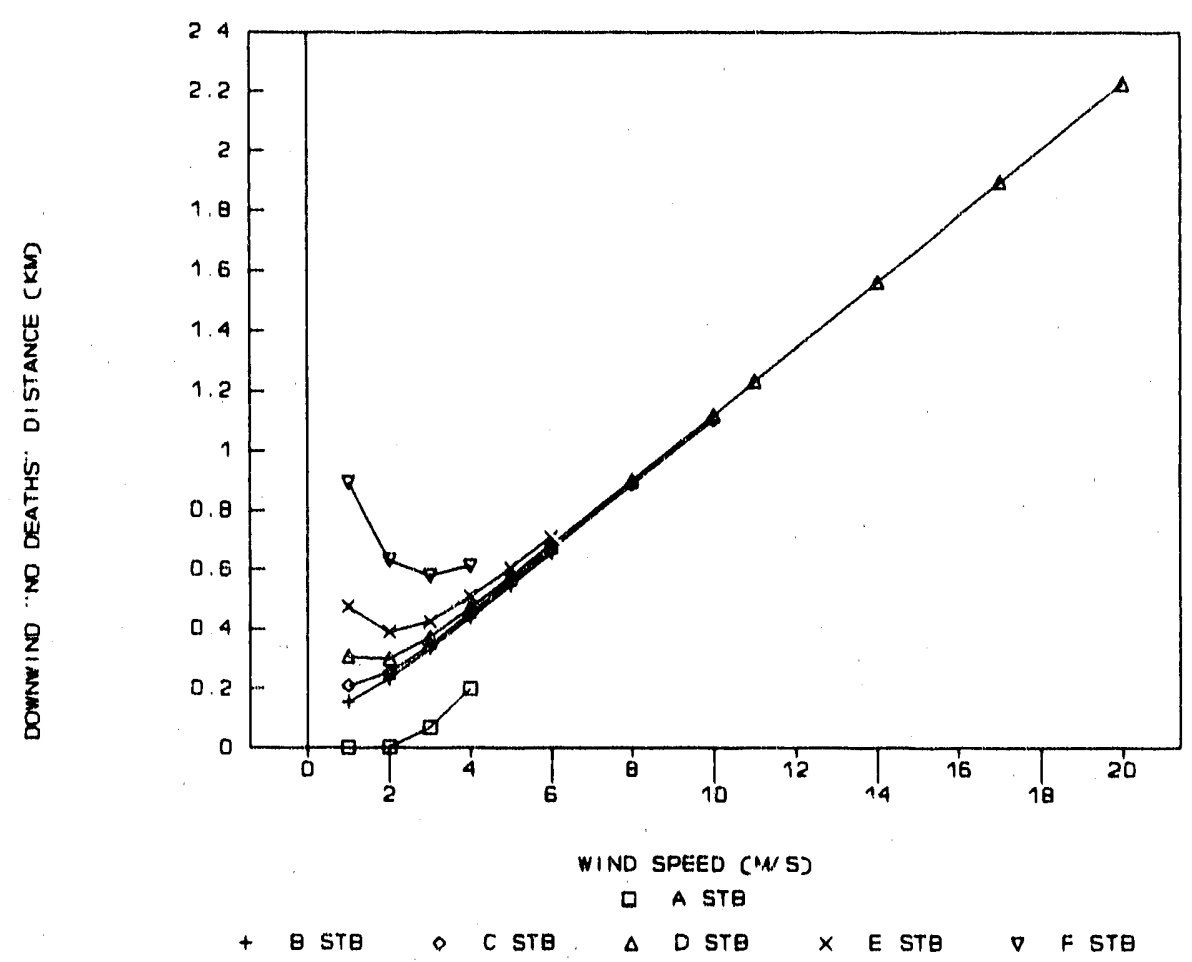

Fig. 4.7. Variable wind spoed (m/t) by stability clase-Scenario 1.

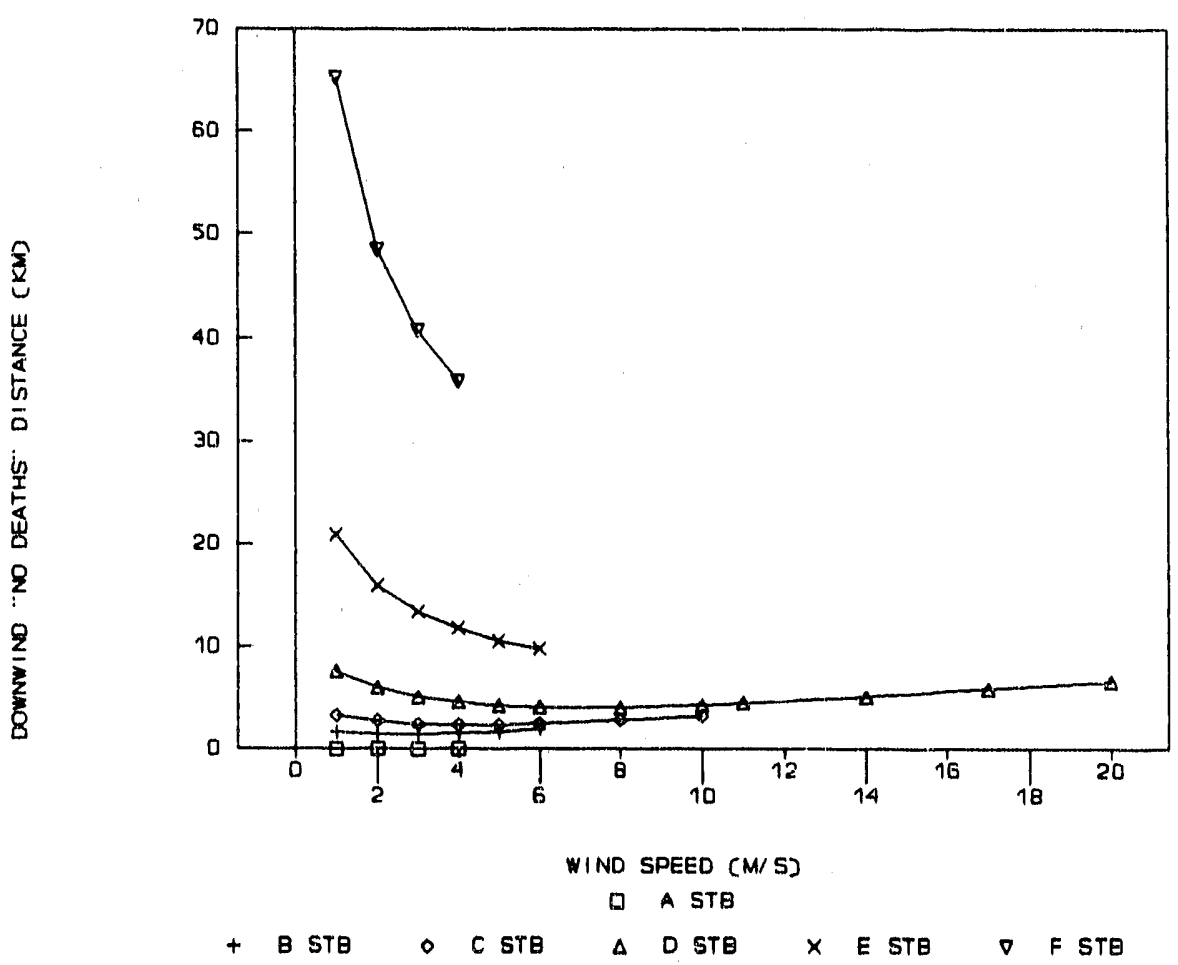

Fig: 4.8. Variable wind speed $(\mathrm{m} / \mathrm{s})$ by stability class-Scenario 2 


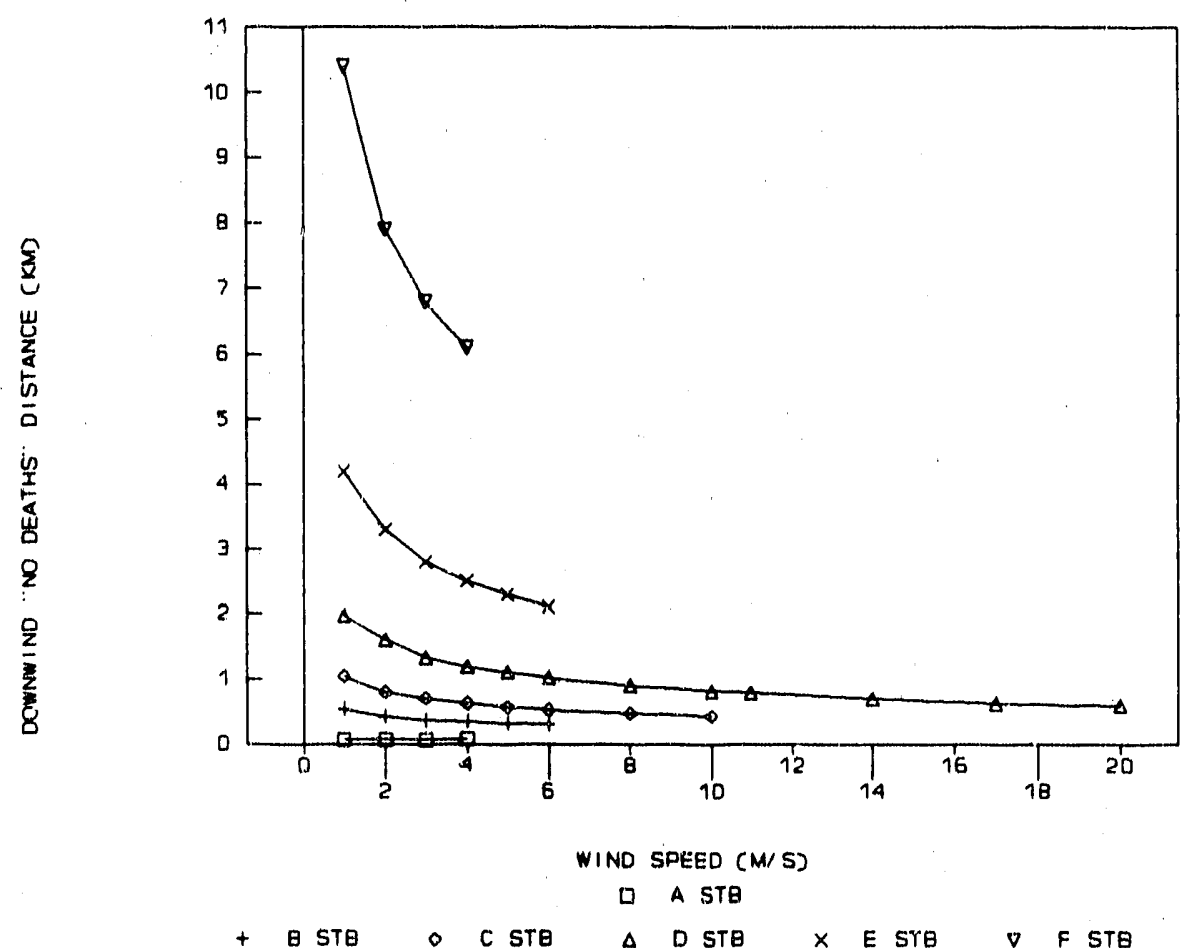

Fig. 4.9. Variable wind speed (m/t) by stability class-Scenario 3.

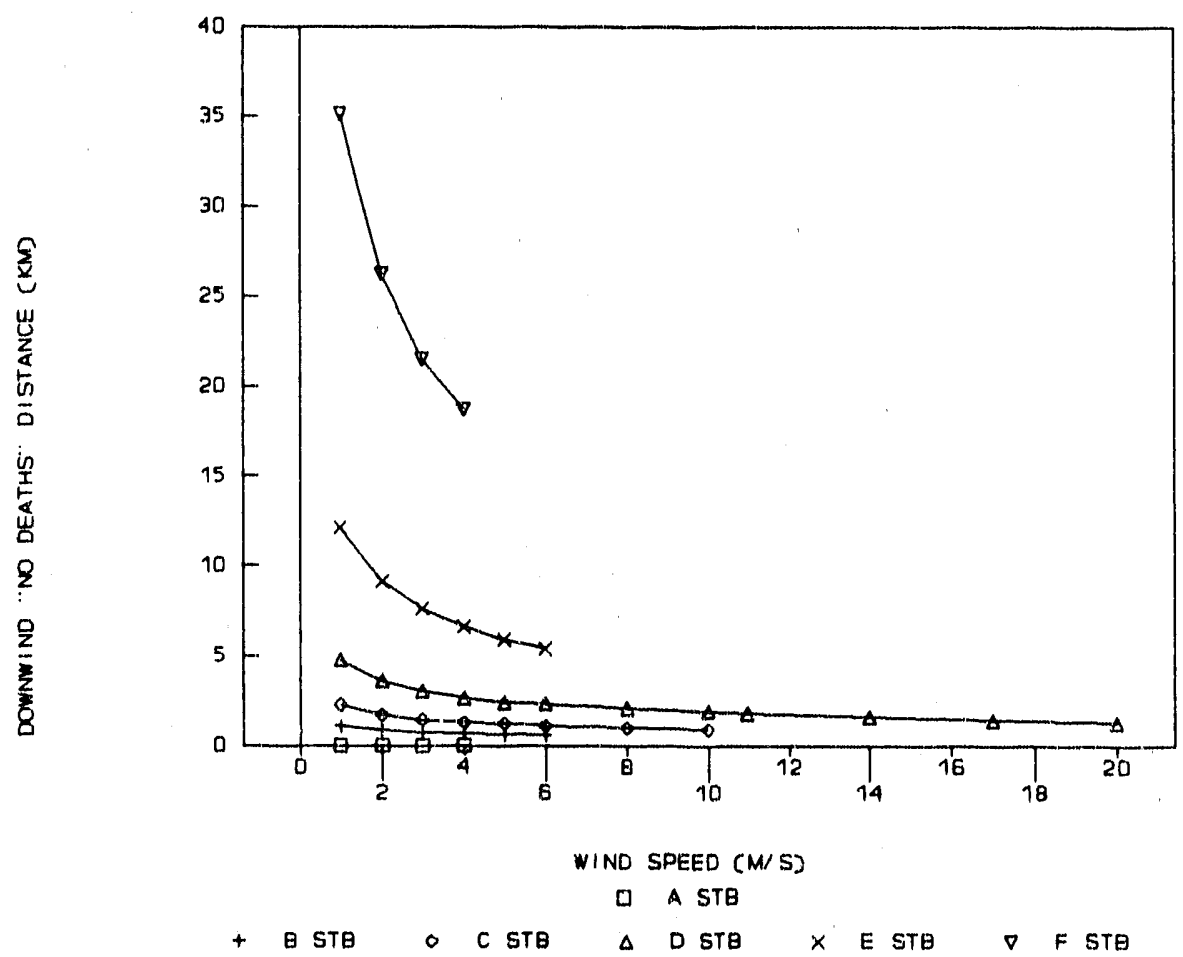

Fig. 4.10. Variable wind speed $(\mathrm{m} / \mathrm{s})$ by stability class-Scenario 4. 


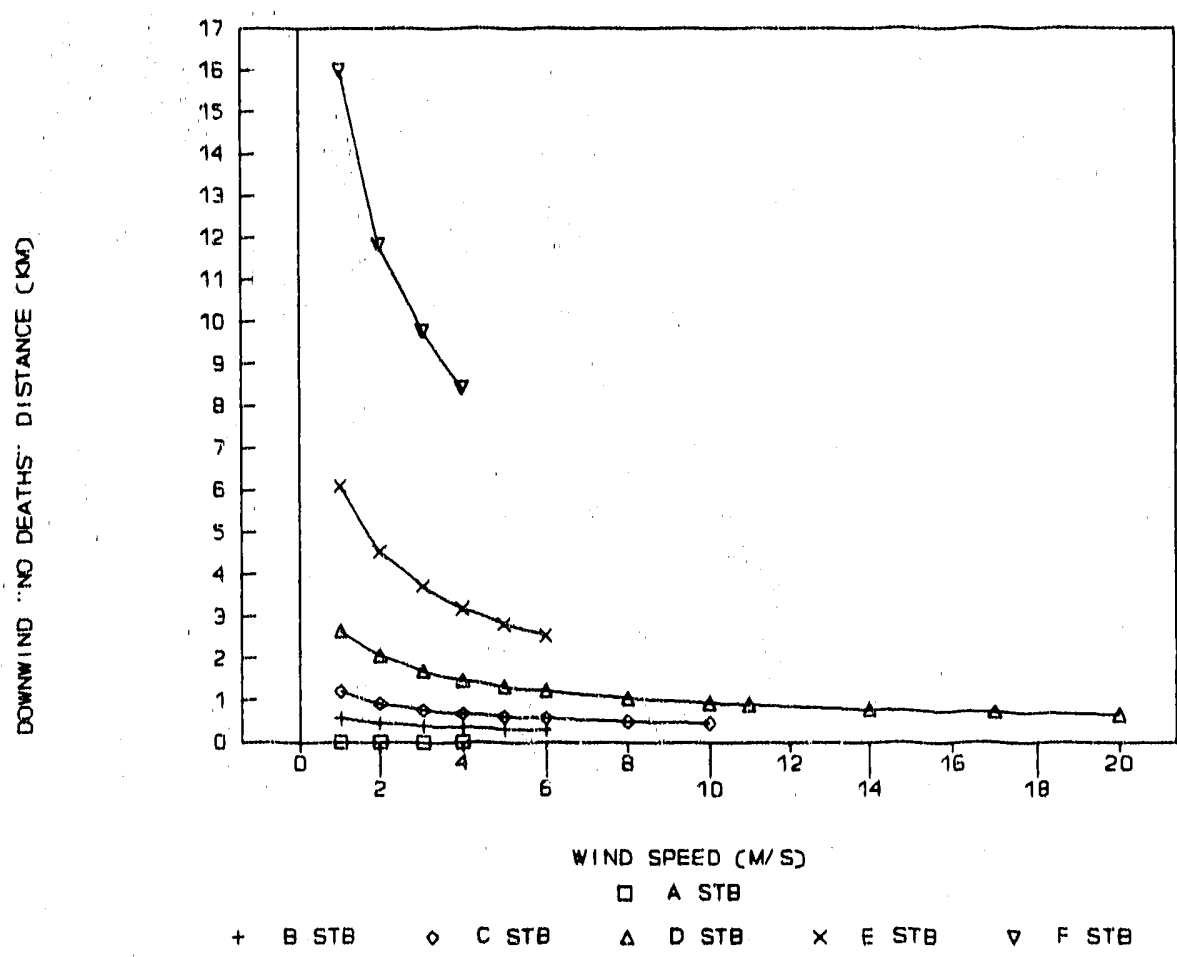

Fig. 4.11. Variable wind speed $(\mathrm{m} / \mathrm{s})$ by stability clase-Scenario 5 .

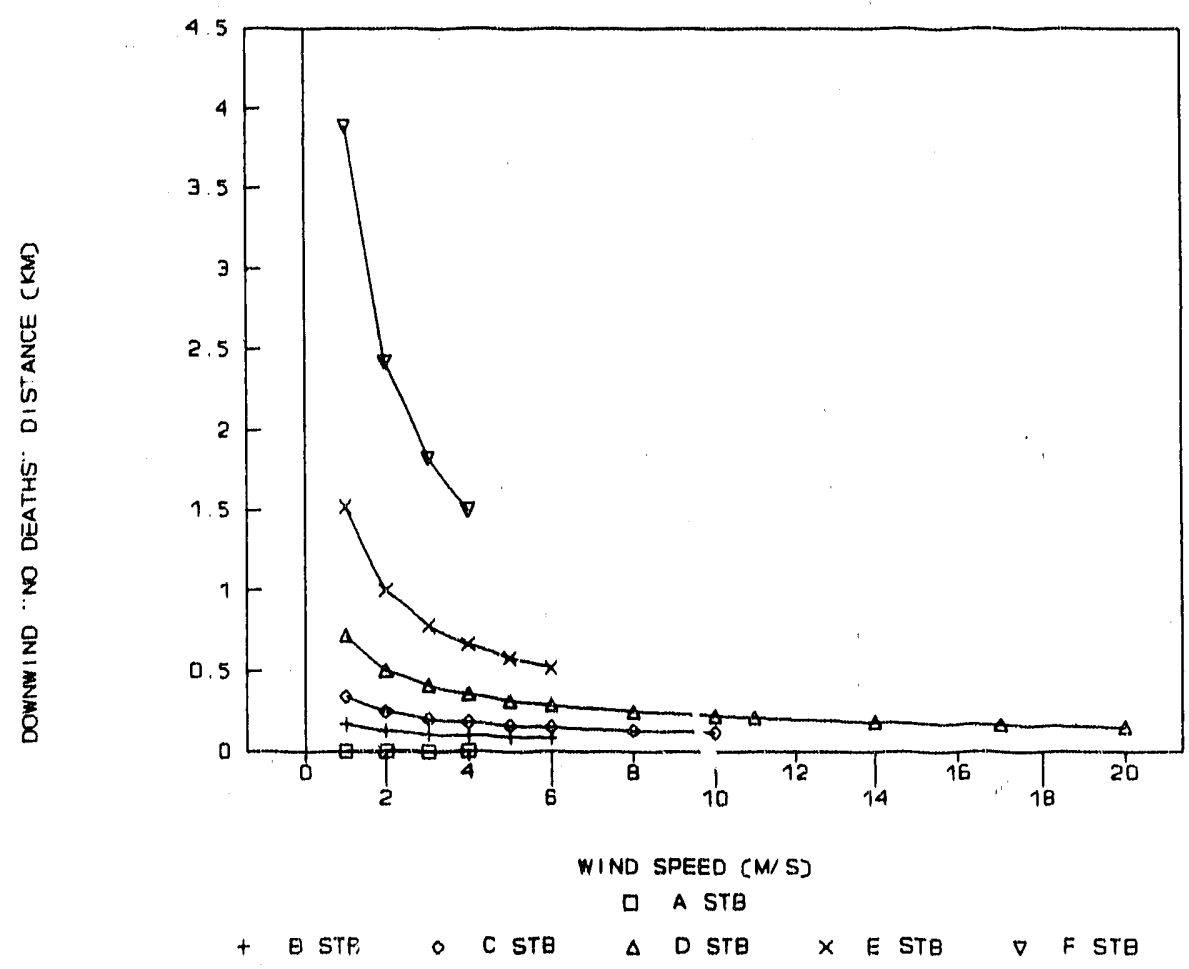

Fig. 4.12 Variable wind speed $(\mathrm{m} / \mathrm{s})$ by stability class-Scenario 6. 
with increasing wind speed) is seen to dominate (Solomon et al. 1970, p. 23). This res it is reflected in Figs. 4.7 and 4.8, where there is a transition from respiratory effects (arta of decreasing downwind distances) to percutaneous effects (area of increasing dowriwind distances). In both cases, the magnitude of the downwind "no deaths" distance is very sensitive to the wind speed, except around the inflection point where the graphs flatten out. Additionally, all stability classes converge to the plot generated by stability $D$. This would indicate that, with higher wind speeds, the sensitivity to stability class is very low.

Scenario 3 is the only scenario where an evaporative component of a complex release is large enough to contribute to the calculation of the overall downwind distance; wind speed is a factor in determining the amount of agent evaporated into the atmosphere. Higher wind speeds generate a greater evaporation rate and an increased source strength.

\subsection{WIND PROFLE EXPONENT}

As indicated above, one component used to calculate the surface deposition velocity is the wind speed profile with height. The main variable that helps to characterize the wind profile is the Frost wind profile exponent developed by R. Frost in 1947 (Sutton 1953). The Frost wind profile exponent is used to describe the wind profile for the turbulent boundary layer found above the surface to the height of the mixing layer and is related to atmospheric stability. As shown in Table 44, a range of exponents was selected for each stability class. Temperature was set at $25^{\circ} \mathrm{C}$ and wind speed was set at $2 \mathrm{~m} / \mathrm{s}$ because CML and WC meteorological conditions cannot be strictly applied to this analysis.

Table 4.4. Frost wind profile exponent number ranges for each stability class

\begin{tabular}{lc}
\hline \multicolumn{1}{c}{ Stability class } & Frost profile exponent number \\
\hline A - very unstable & $0.01-0.20$ \\
B - unstable & $0.05-0.25$ \\
C - slightly unstable & $0.10-0.30$ \\
D - neutral & $0.15-0.35$ \\
E - slightly stable & $0.20-0.40$ \\
F - stable & $0.25-0.45$ \\
\hline
\end{tabular}


Figures $4.13-4.18$, corresponding to accident scenarios $1-6$ respectively, show by stability class the relationship between the wind profile exponent and downwind distance. Except with A stability, little sensitivity to downwind distance is generated by the wind profile exponent. For A stability, the downwind "no deaths" distance drops to zero with increasing exponents because a higher exponent implies both higher deposition velocity and smaller quantities of vapor. Therefore, not enough vapor is available to provide a downwind "no deaths" distance greater than $10 \mathrm{~m}$. For all scenarins, a wind profile exponent of 0.25 , the value chosen for accidental release assessment in the CSDP FP I is, corresponds to a downwind distance less than $10 \mathrm{~m}$ during $A$ stability. For $A$ stability, it is more appropriate to use an exponent value of 0.10; for B stability, 0.15 ; for $\mathrm{C}$ stability, 0.20; for E stability, 0.30; and for F stability, 0.35. These values correspond to the exponents originally developed by $R$. Frost. An exponent value of 0.25 is appropriate for D stability.

For most other cases, the downwind "no deaths" distance decreases slightly or remains the same with an increase in the wind profile exponent. However, there is a slight increase in downwind distance from the second-to-last to the last value of the exponent for stabilities $\mathrm{E}$ and $\mathrm{F}$ in scenario 2. For these cases, the deposition velocity reaches a minimum and begins to ircrease, because the amount of vapor depleted has reached a maximum and is to beginining to decrease. The function determining the surface deposition velocity is complex, and the wind profile exponent is involved in the function a number of times (Whiteacre et al. 1987, p. 76). Regardless of the slight increase or decrease in the downwind distance, the sensitivity to wind profile exponent is very smail.

\section{SURFACE ROUGHINES HEIGHT}

Surface roughness height is proportional (approximately one-tenth) to the mean height of protuberances (e.g., grass, trees, and buildings) that occur on the surface.

Surface roughness height is used, together with the wind profile exponent, to calculate the surface deposition velocity. An increase in the surface roughness height leads to a greater amount of generated mechanical turbulence. With increased turbulence, the vertical and horizontal dispersion of pollutants is enhanced, and less surface deposition will occur. Thus, an increase in the surface roughness parameter leads to a larger downwind distance because the surface deposition velocity is smaller (Whiteacre et al. 1987, p. 76). This is opposite of the turbulence effect characterized by the generalized stability parameter. As indicated earlier, the generalized stability parameter relates stability to atmospheric turbulence. A lower value of the stability parameter represents a more stable atmosphere with less turbulence. A lower value of the stability parameter leads to a lower deposition velocity; therefore, a longer downwind distance is computed under higher stability. D2PC calculates a longer downwind distance with less turbulent conditions in terms of the generalized stability parameter, but D2PC calculates a shorter downwind distance with less turbulent conditions in terms of the surface roughness height. 


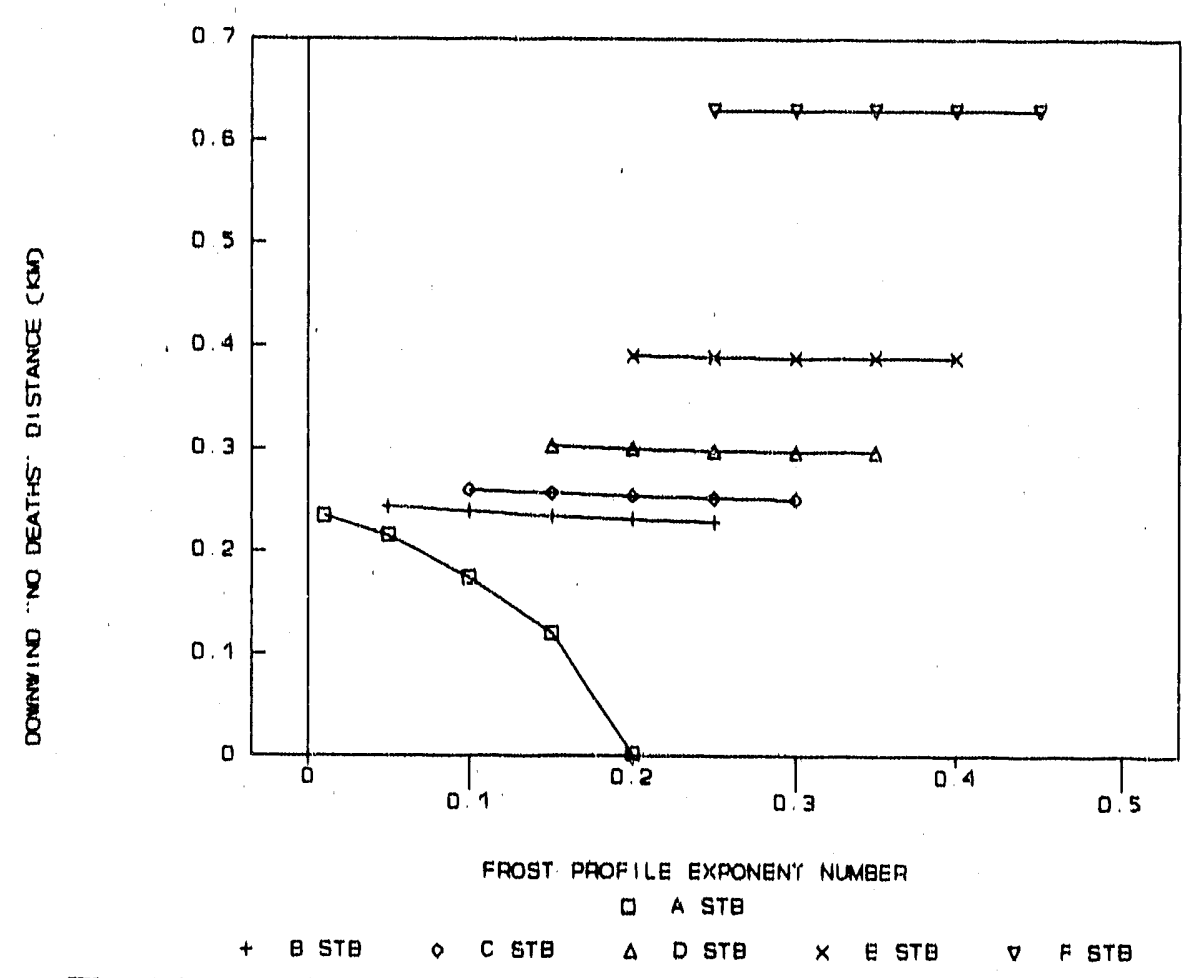

Fig 4.13. Variable wind profile exponent by stability claw-Sesnario 1.

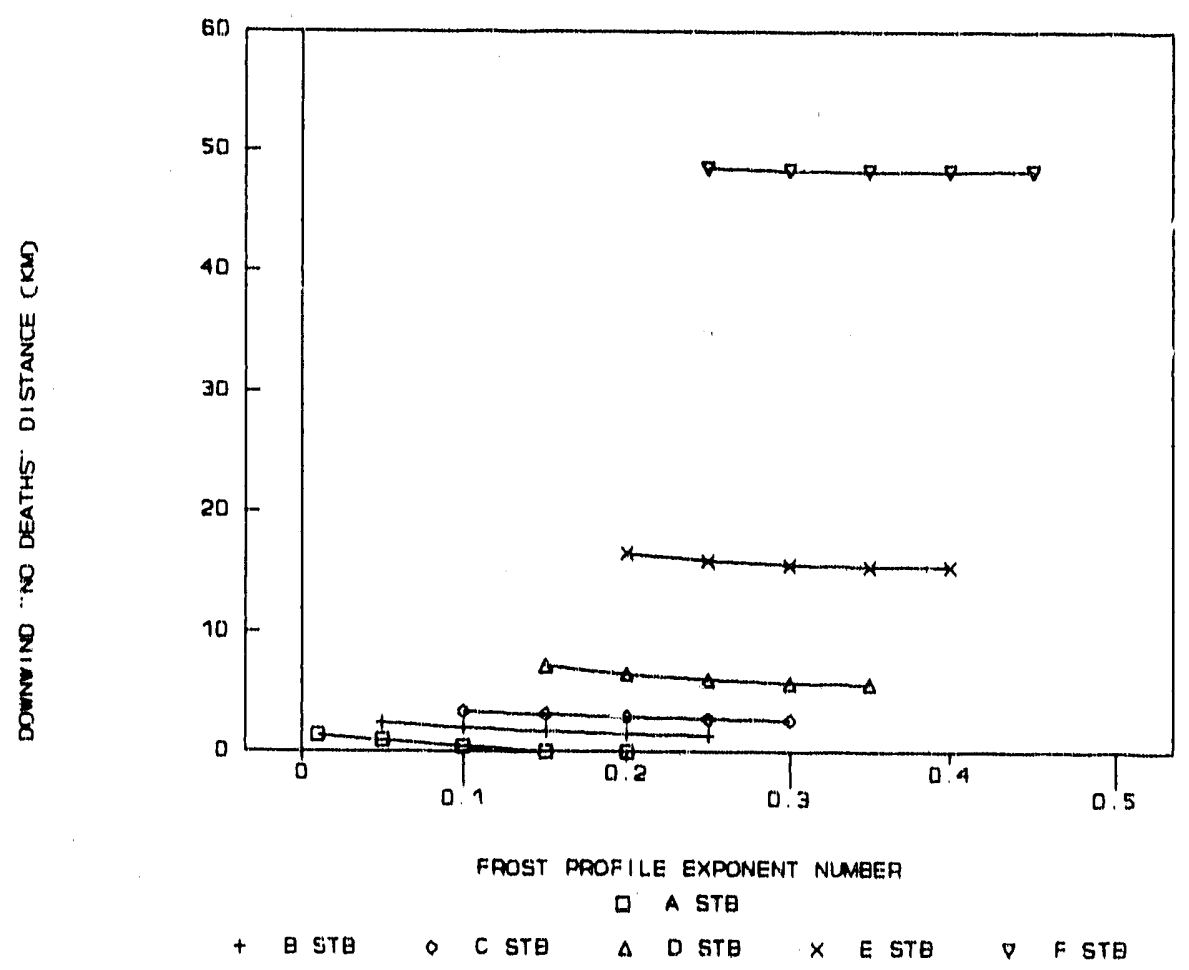

Fige 4.14. Variable wind profile exponent by stability claw-Scenario 2 


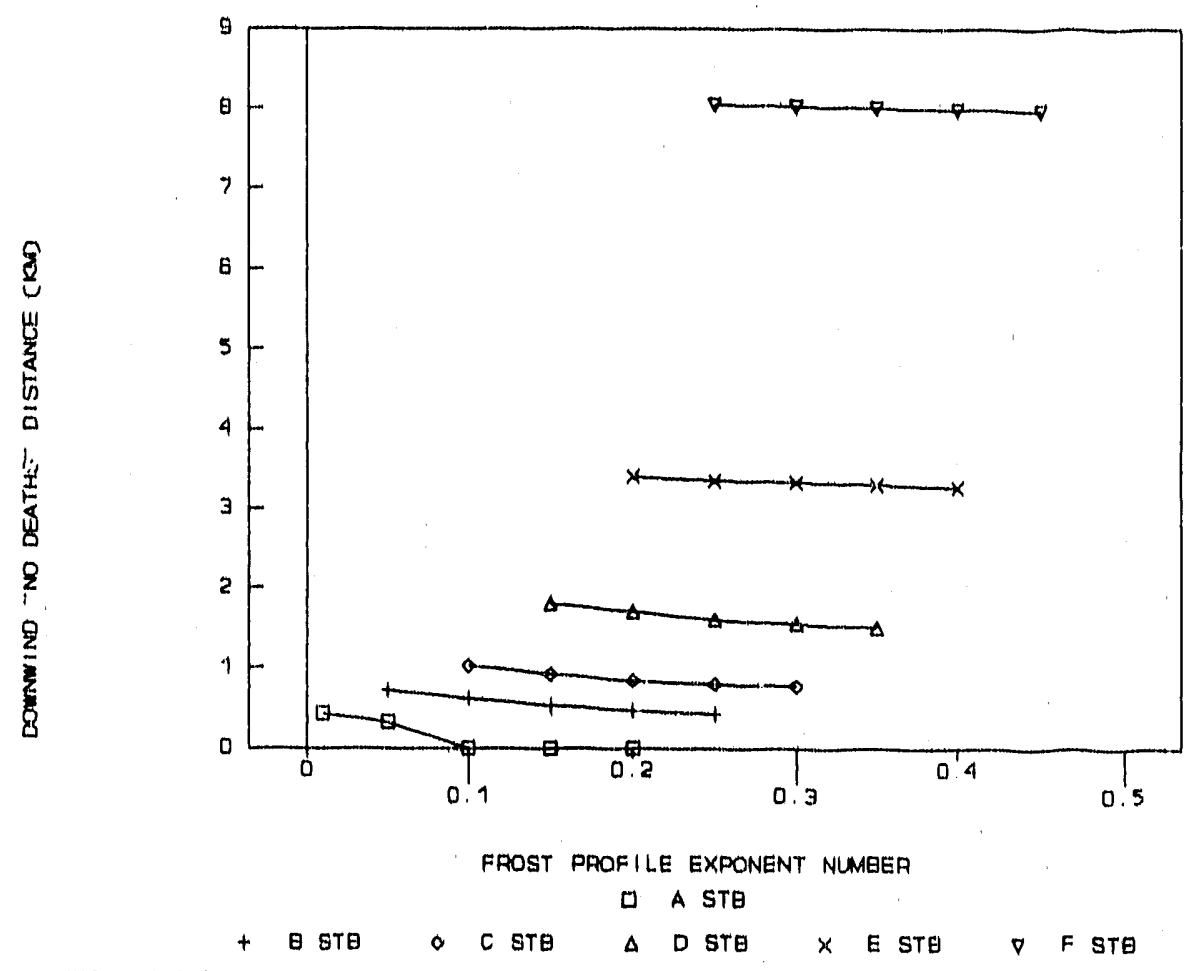

Fig. 4.15. Variable wind profile exponent by stability clase-Scenario 3.

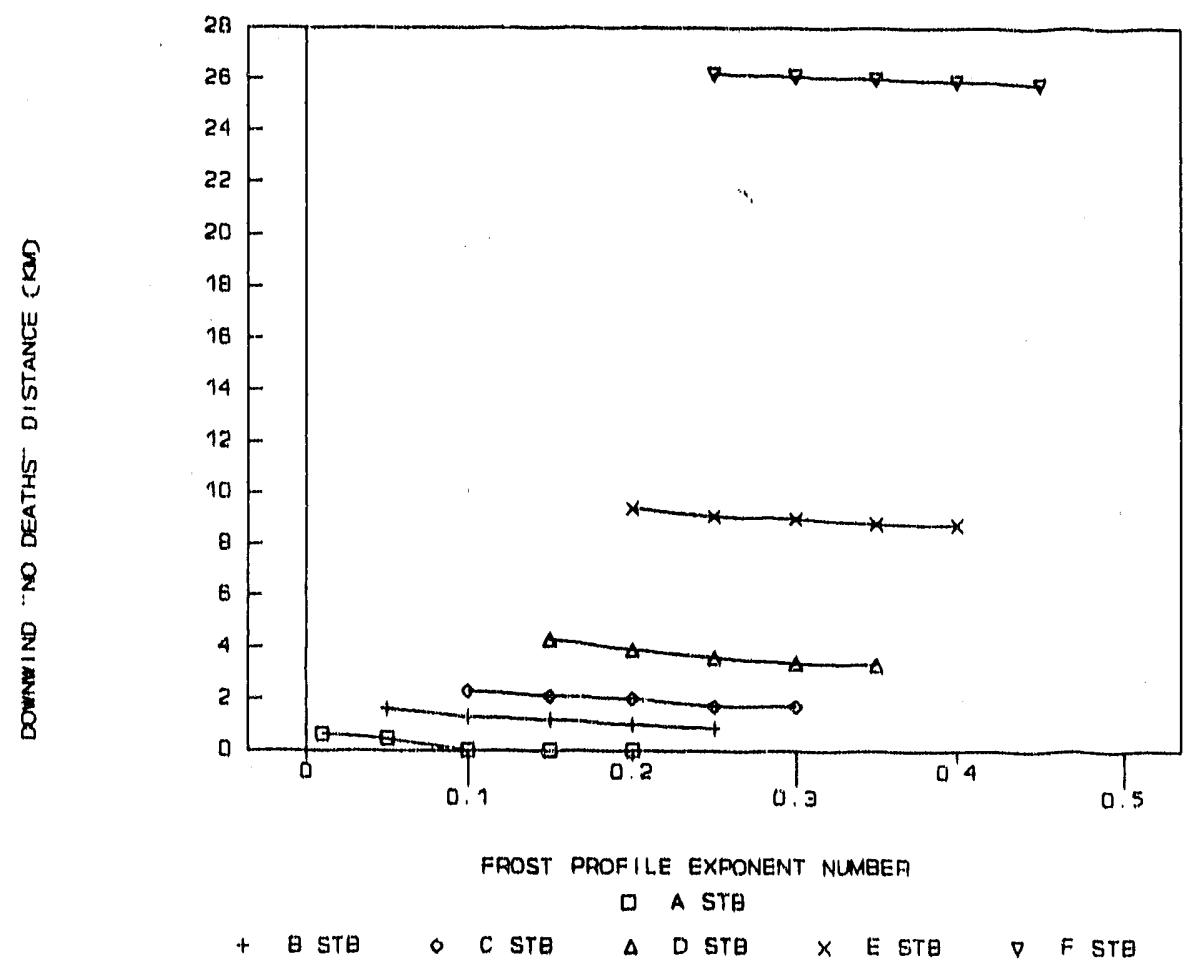

Fig. 4.16. Variable wind profile exponent by stability class-Scenario 4. 


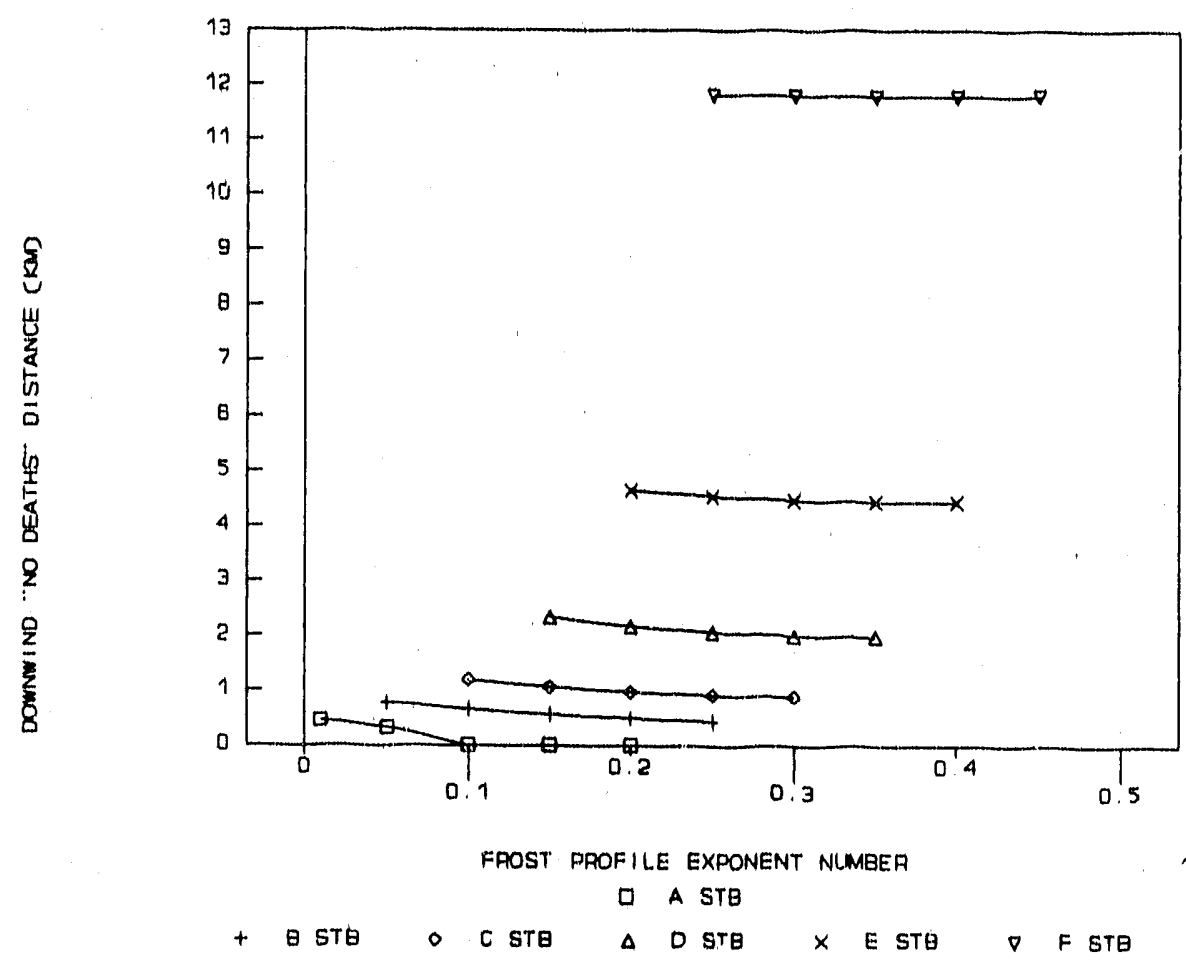

Fig. 4.17. Variable wind profile exponent by stability clase-Scenario 5.

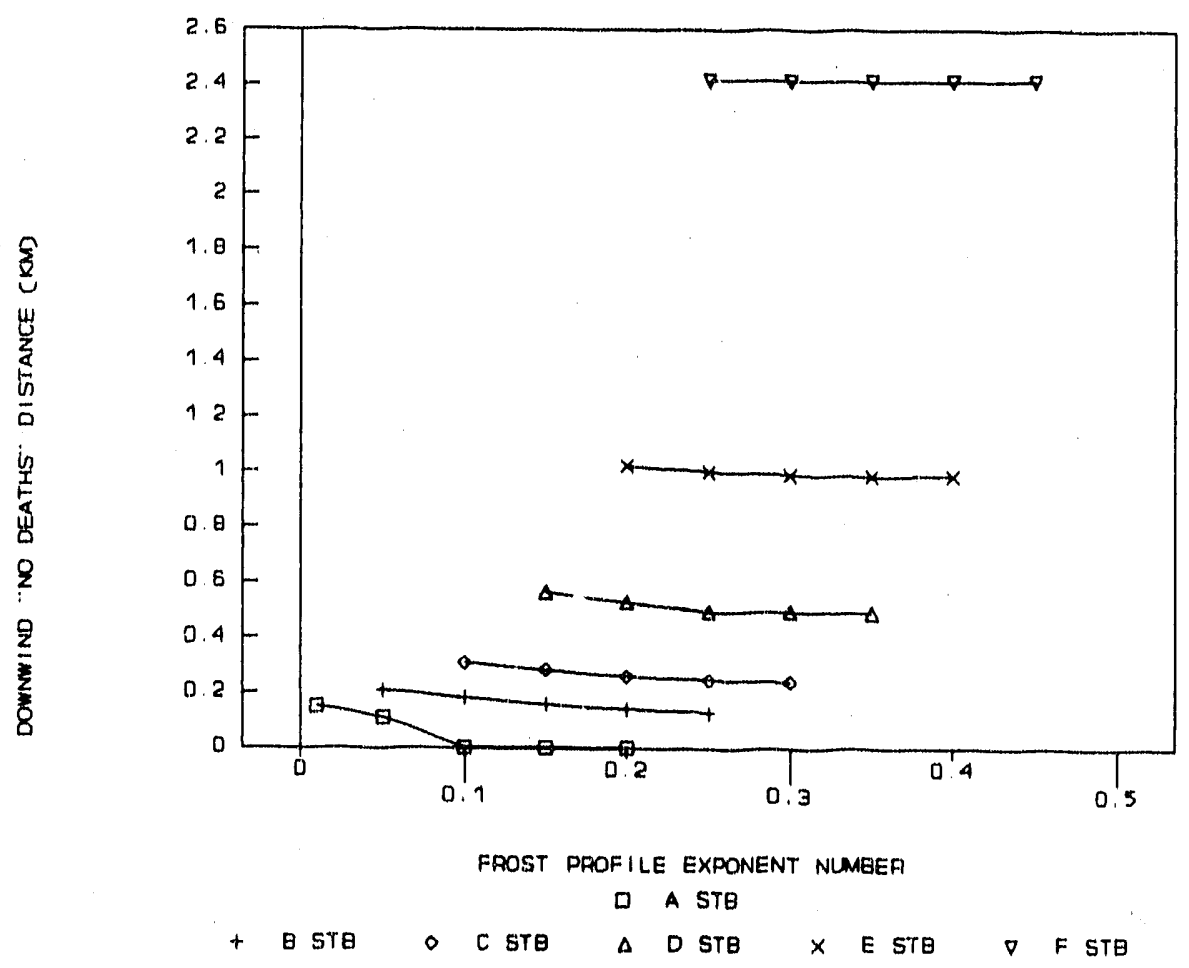

Fig- 4.18. Variable wind profile exponent by stability clane-Scenario 6. 
Figures 4.19-4.24 show how changes in surface roughness paramelers, under both WC and CML meteorological conditions, affect downwind distances for each accident scenario. The input values for surface roughness and their corresponding surface features are indicated in Table 4.5 (after Sutton 1953, p. 233).

Table 4.5. Surface roughneas beights with corresponding surface features

\begin{tabular}{cl}
\hline Surface roughness height (cm) & \multicolumn{1}{c}{ Surface feature } \\
\hline 0.001 & Smooth mud flats, ice \\
0.01 & Smooth desert \\
0.1 & Lawn, grass up to $1 \mathrm{~cm}$ high \\
1.0 & Grass up to $10 \mathrm{~cm}$ high \\
10.0 & Grass up to $50 \mathrm{~cm}$ high \\
50.0 & Farmiand \\
100.0 & Woods \\
500.0 & Cities \\
\hline
\end{tabular}

WC meteorological conditions exhibit less sensitivity to surface roughness parameters than CML meteorological conditions for all scenarios. For a more stable atmosphere, the vertical dispersion is reduced, and the mechanical mixing effects caused by surface roughness height have less impact on the overall downwind distance.

There is a wide range of sensitivity between scenarios. For all scenarios, the largesit changes in downwind distance occur when the surface roughness height: is less than $1 \mathrm{~cm}$. Scenarios 1 and 6 display the least sensitivity, both of which involve a nelatively small amount of agent released. Scenarios 2 and 4, both of which involve complex release modes, display the greatest sensitivity. These latter two scenarios involve a relatively large amount of agent released.

\subsection{EVAPORATTVE RELLASE VARIABLES}

Scenarios 2, 3, and 4 all involve an evaporative component in a complex release; however, only in scenario 3 is the amount of agent released to the atmosphere by evaporation large enough to contribute significantly to the total calculation of a downwind "no deaths" distance. Two variables that contribute to the calculation of downwind distance during an evaporative release are surface temperature and surface atmospheric pressure. These variables are used to calculate an effective evaporation rate (Whiteacre et al. 1987, p. 38). 


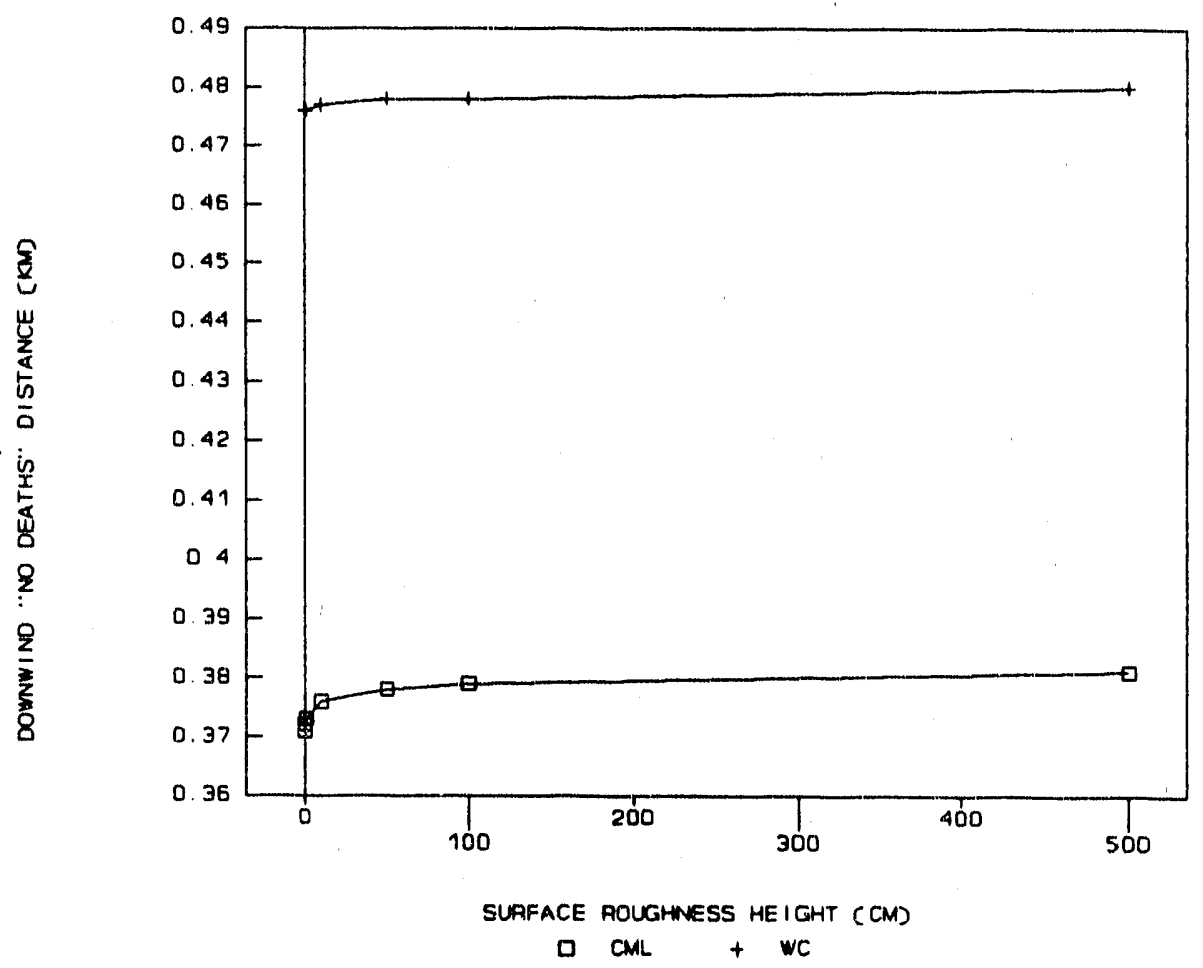

Fig. 4.19. Variable roughneas height (cm)-Scenario 1.

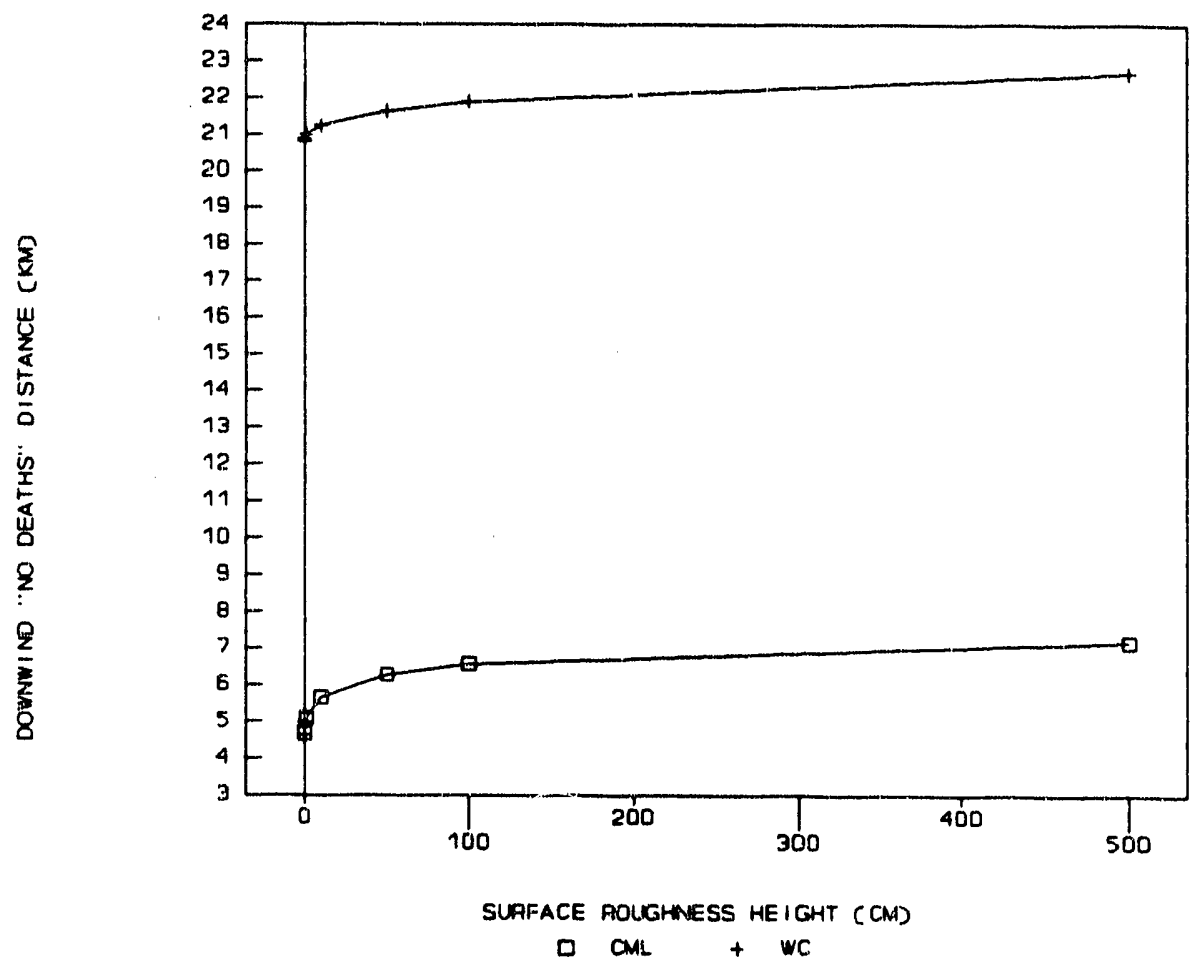

Fig. 4.20. Variable roughneas height (cm)-Scenario 2 


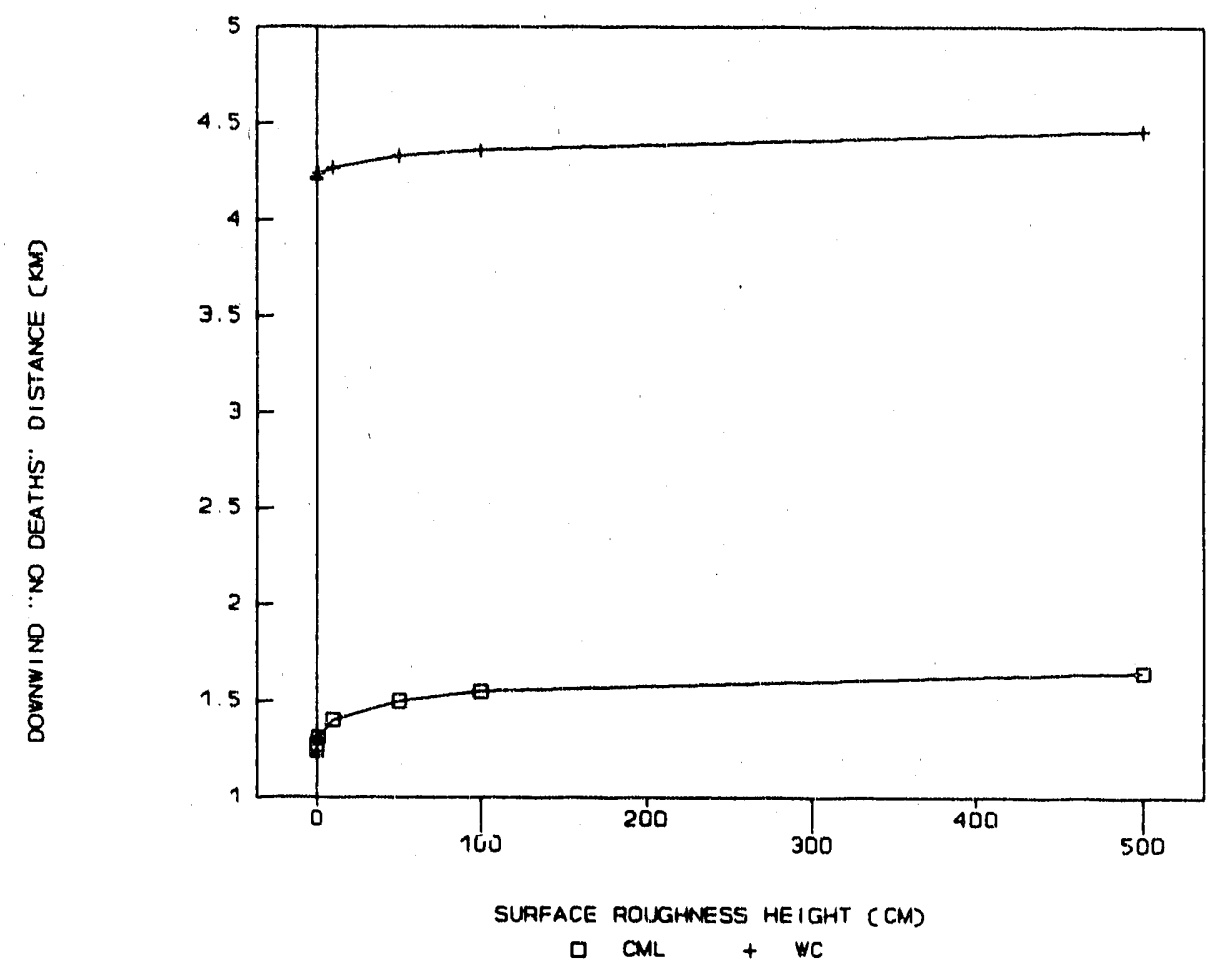

Fig 4.21. Variable roughneas height (cm)-Scenario 3.

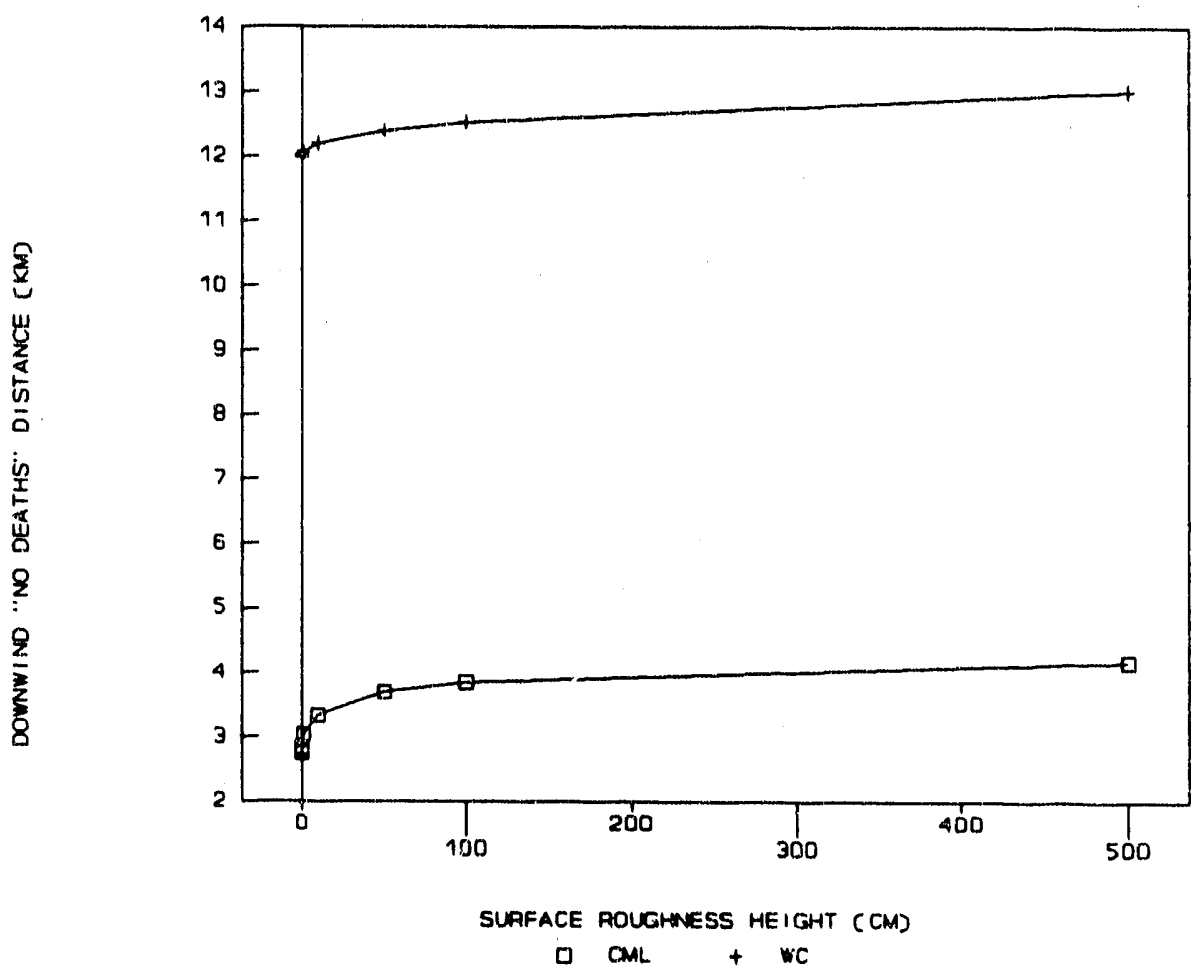

Fig. 4.22 Variable roughness height (cm)-Scenario 4. 


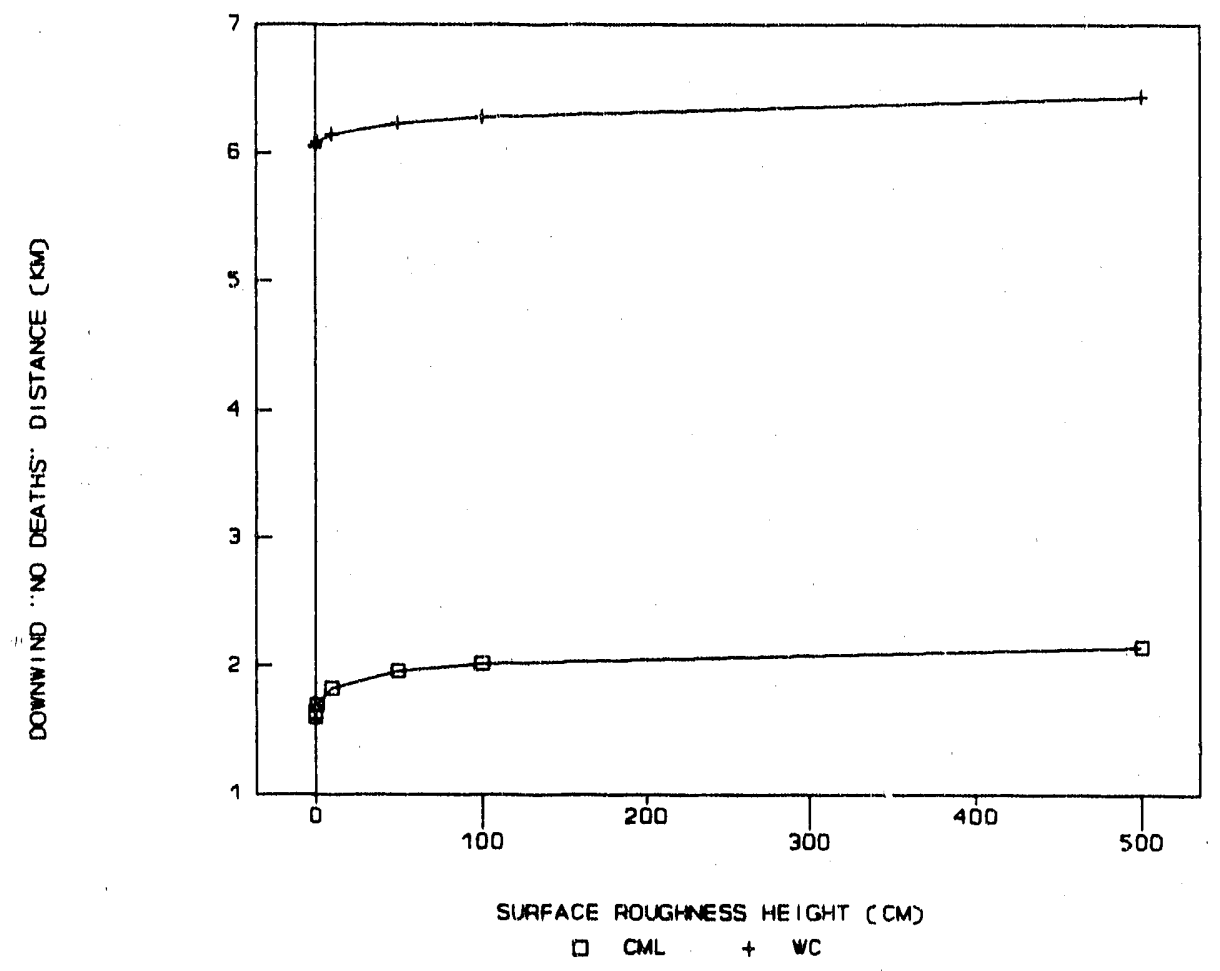

Fig. 4.23. Variable noughneas height (cm)-Scenario 5.

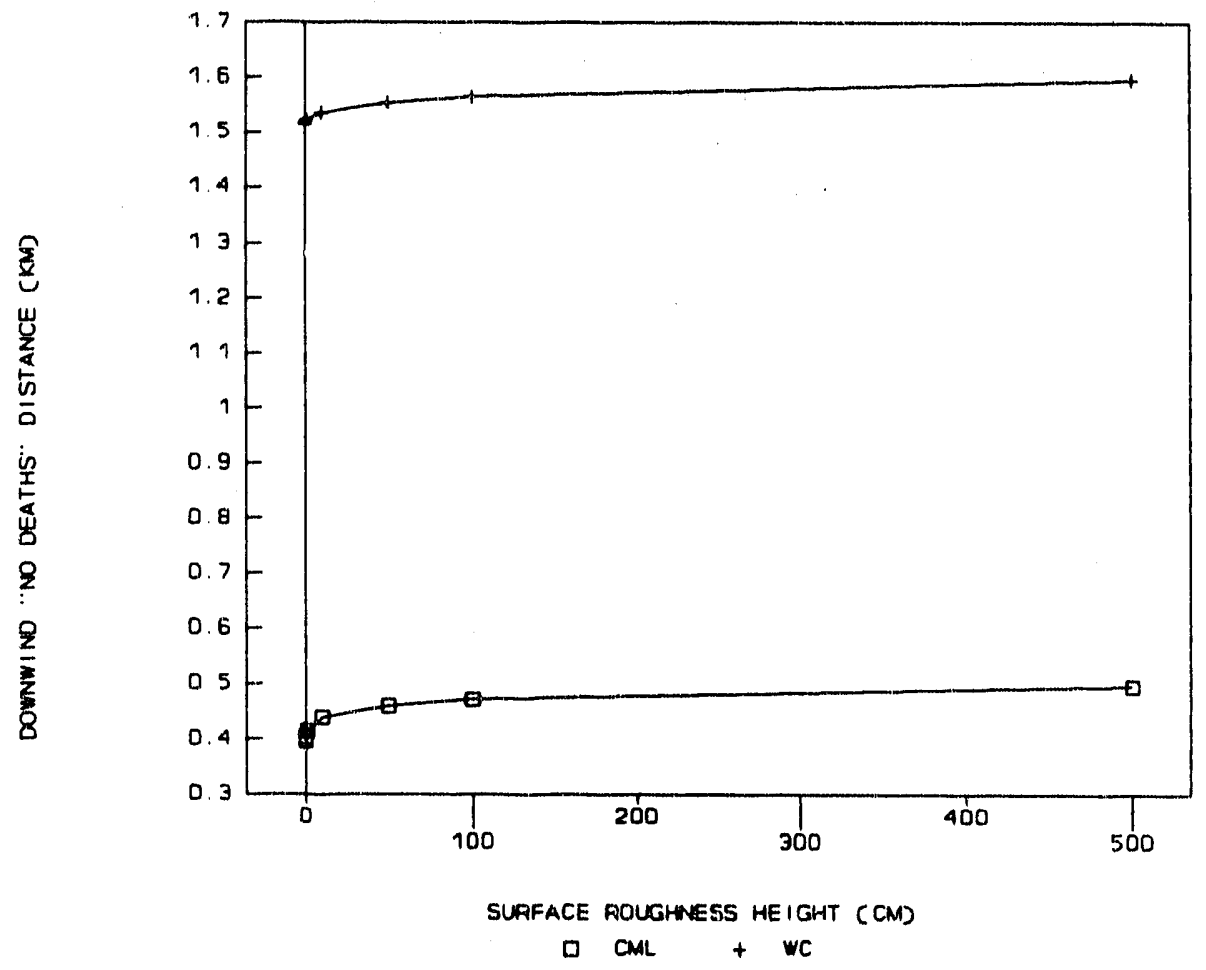

Fig. 424. Variable roughness beight $(\mathrm{cm})$-Scenario 6. 
Figure 4.25 shows the effect of varying surface temperature on the downwind "no deaths" distance. The two plots shown in Fig. 4.25 are for WC and CML meteorological conditions. The range of temperatures for CML conditions is between 0 and $40^{\circ} \mathrm{C}$, and between 10 and $50^{\circ} \mathrm{C}$ for WC conditions. These ranges were centered around the values used during the accidental release assessment in the CSDP FPEIS for CML $\left(20^{\circ} \mathrm{C}\right)$ and WC $\left(30^{\circ} \mathrm{C}\right)$ conditions.

The sensitivity is greatest for WC meteorological conditions where there is a $500 \mathrm{~m}$ downwind distance increase for a $40^{\circ} \mathrm{C}$ rise in temperature. The downwind distance increases slowly at the lower end of the temperature range and increases more rapidly at the higher end of the temperature range. The sensitivity is less for CML conditions where there is an increase in the downwind distance of $250 \mathrm{~m}$ for a $40^{\circ} \mathrm{C}$ rise in temperature.

Figure 4.26 depicts the sensitivity of surface pressure within the D2PC model. As with temperature, two plots are shown that correspond to WC and CML meteorological conditions. The selected values represent a wide range of surface atmospheric pressures. The lowest surface pressure analyzed is $300 \mathrm{~mm} \mathrm{Hg}$, which corresponds to surface conditions at altitudes in excess of $20,000 \mathrm{ft}$. The highest surface pressure analyzed is $800 \mathrm{~mm} \mathrm{Hg}$, which corresponds to surface conditions found in the most intense high pressure systems at sea level.

There is very small sensitivity over this range of surface pressures. When the evaporative release component is isolated, sensitivity is slightly greater over this range but is still relatively small. For a typical range found at a particular site (e.g. $730-790 \mathrm{~mm}$ $\mathrm{Hg}$ ), there is virtually no sensitivity. The surface pressure parameter is used in the calculation of many terms (i.e., air density and diffusivity) that appear in the evaporation rate equation. The effect of surface pressure on the evaporation rate is minimized by the counteracting effect of these terms.

\subsection{INHALATION-DEPOSITION VARIABLES}

D2PC considers the combined affects of vapor inhalation and aerosol impaction. The skin penetration factor is critical in the calculation of doses received by aerosol impaction, and the breathing rate is critical in the calculation of doses received by vapor inhalation. The breathing rate is used by the model one of two ways: (1) as part of the inhalation-deposition algorithm, or (2) to adjust the dose of interest used to determine a particular downwind distance. For instantaneous releases of VX, most of the agent is transported as aerosols, and an empirically derived equation is used by D2PC to calculate the dose (Whiteacre et al. 1987, p.43). For all other releases, the critical dose to determine a particular downwind distance ("no deaths" for this analysis) is adjusted based on the breathing rate. The standard dose for each agent is based on a breathing rate of 25 liters per minute. If the breathing rate is less or greater than 25 liters per minute, the critical dose is altered by the ratio of the standard breathing rate to the input breathing rate. If the breathing rate is less than 25 liters per minute, the dose of interest is increased; if the breathing rate is greater than 25 liters per minute, the dose of interest is decreased. 


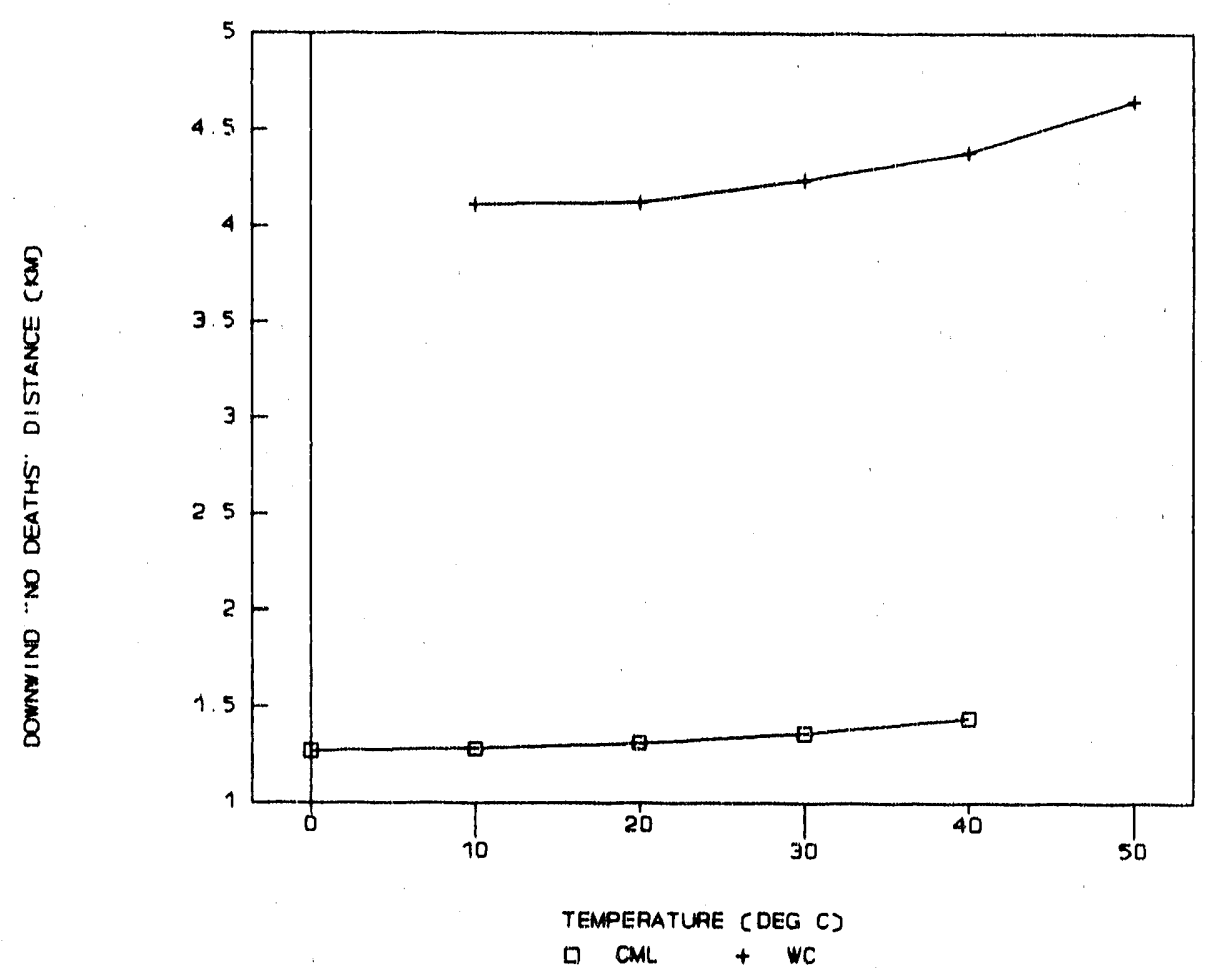

Fig. 4.25. Variable temperature $\left({ }^{\circ} \mathrm{C}\right)$-Scenario 3.

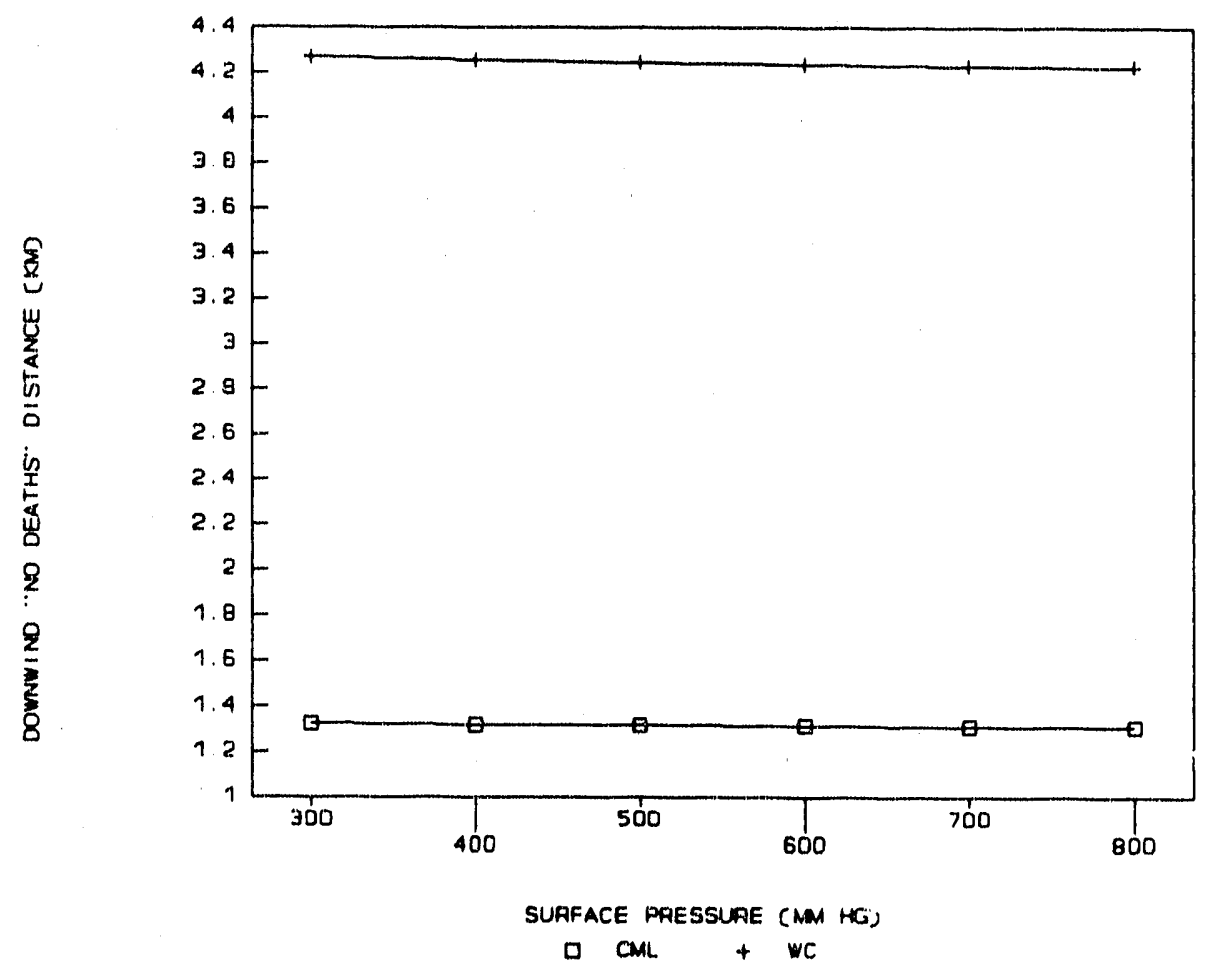

Fig 4.26. Variable surface pressure ( $\mathrm{mm} \mathrm{Hg}$ )-Scienario 3. 
Figures 4.27 and 4.28 show the downwind distance sensitivity to breathing rate. Breathing rates were selected in conjunction with a range of activity levels among men of various age groups (Snyder et al. 1974, p. 346). Table 4.6 shows the selected breathing rate values and the corresponding activity levels.

Table 4.6. Selected breathing rates and corresponding activity levels

\begin{tabular}{cl}
\hline Breathing rate (liters/min) & \multicolumn{1}{c}{ Activity level } \\
\hline 0.5 & Resting newborn \\
1.0 & Resting infant \\
2.5 & Light activity infant \\
5.0 & Resting child \\
7.5 & Resting adult male \\
15.0 & Light activity child \\
20.0 & Light activity adult male \\
25.0 & Moderate activity adult male \\
30.0 & Heavy activity adult male \\
\hline
\end{tabular}

The six plots shown in Figs. 4.27 through 4.32 are for WC and CML meteorological conditions. An interesting effect is shown for scenario 1 (Fig. 4.27). Scenario 1 represents an instantaneous release of VX in which the breathing rate is incorporated into the inhalation-deposition equation. In this relationship, the combined effects are considered by converting to an intravenous dose; the inhaled dose component is added to the percutaneous dose component to produce an overall intravenous dose. The breathing rate term is directly proportional to the intravenous dose. With a higher intravenous dose, given the same amount of agent released, the downwind "no deaths" distance is greater. In the range of low breathing rates, the downwind "no deaths" distance is actually greater for CML conditions than the downwind "no deaths" distance for WC conditions. When the breathing rate is small, the percutaneous effect term dominates the calculation and the downwind "no deaths" distance is determined largely by the wind speed. Since CML meteorological conditions have a greater wind speed than WC meteorological conditions, the downwind distance is greater for the former condition when the breathing rate is small. As the breathing rate increases, the inhaled dose effect begins to dominate the overall calculation of downwind distance. For scenario 2, this graph is similar, but WC downwind distances are always greater than CML downwind distances. Scenario 2 is a complex release of VX; the semi-continuous portion of the release reduces the effects of inhalatio -deposition.

The sensitivity to breathing rate for scenario 1 is high for CML conditions and low for WC conditions. The effect of higher wind speed in CML conditions compared to WC 


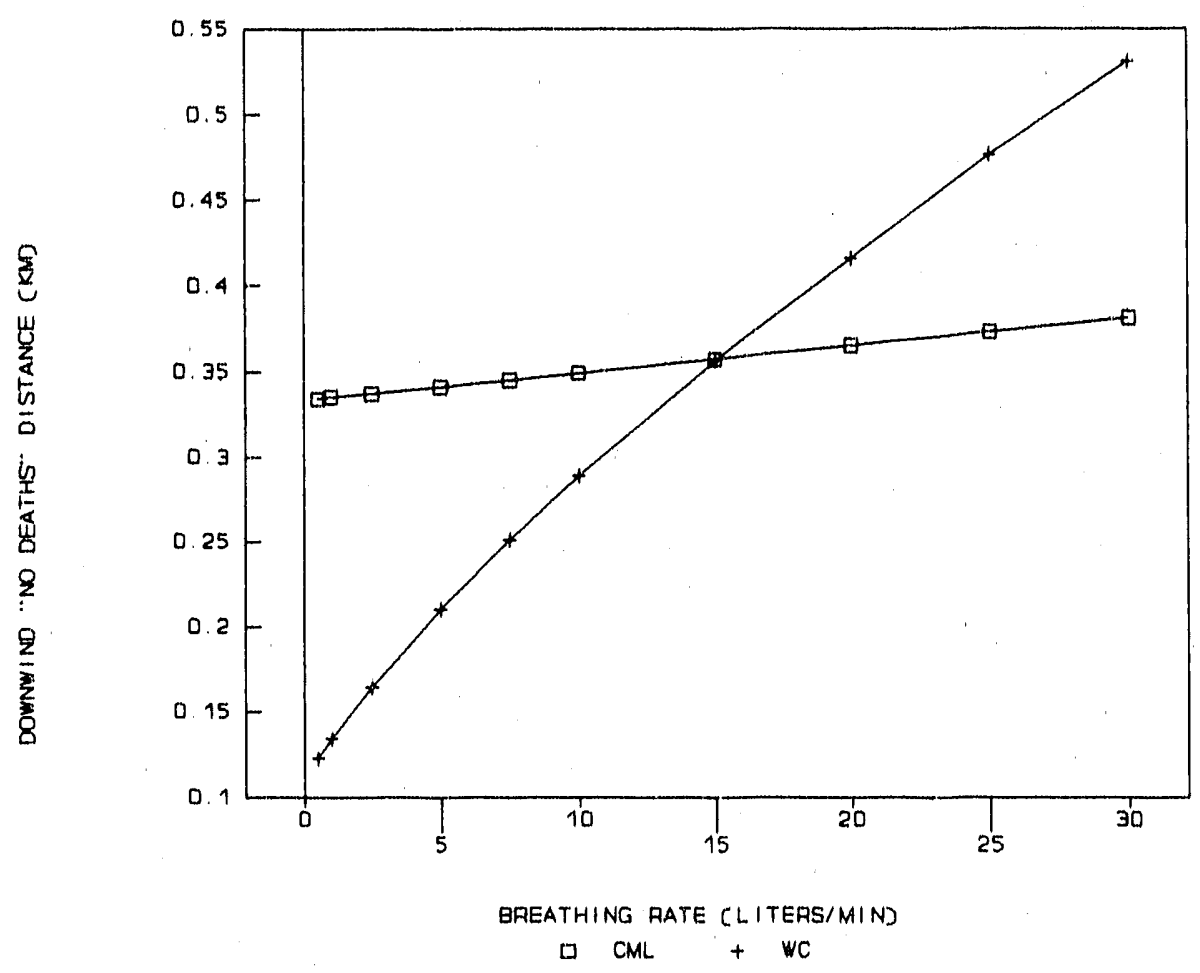

Fig. 4.27. Variable breathing rate (liters/min)-Scenario 1.

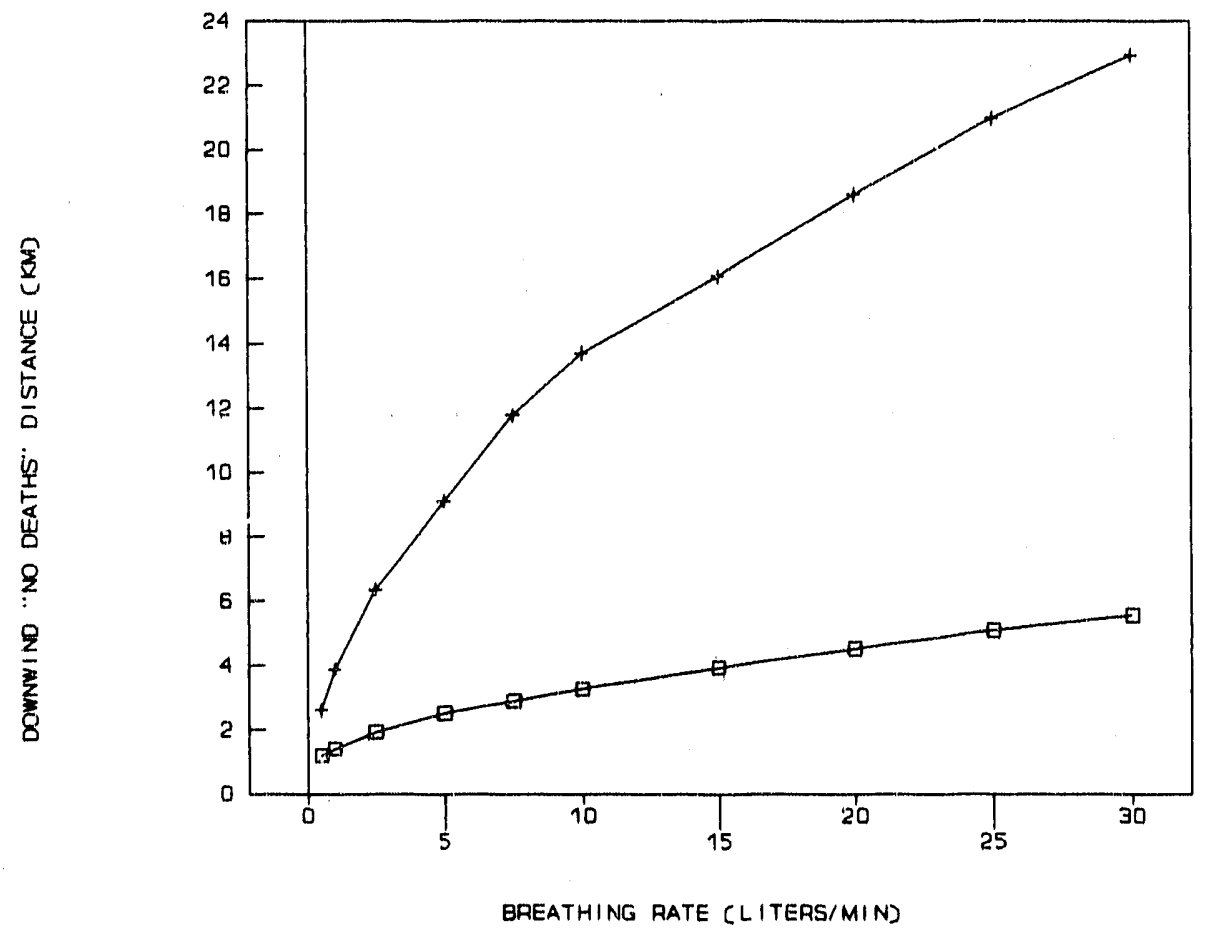

$\square C M L+W C$

Fig. 4.28. Variable breathing rate (liters/min)-Scenario 2 


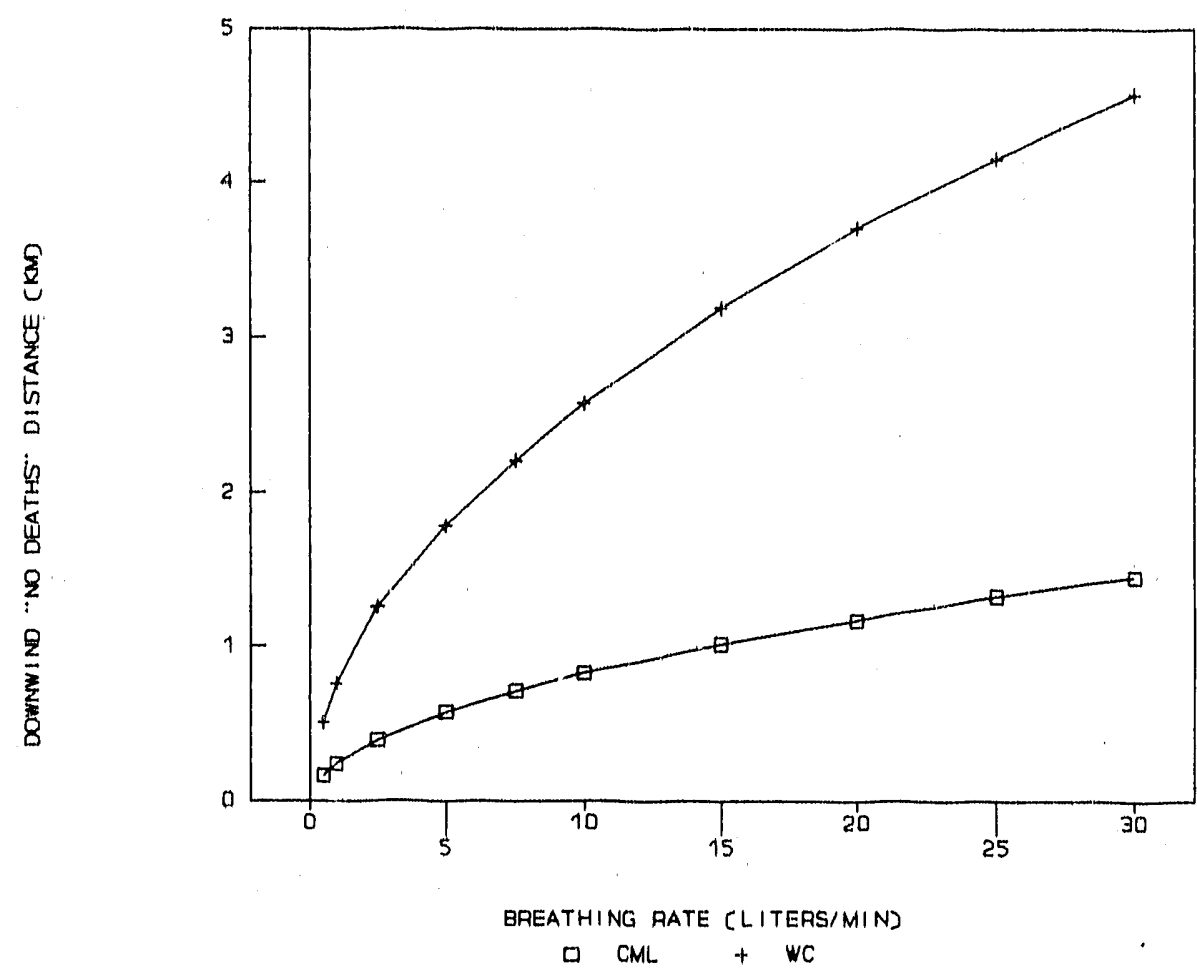

Fig. 4.29. Variable breathing rate (liters/min)-Scenario 3.

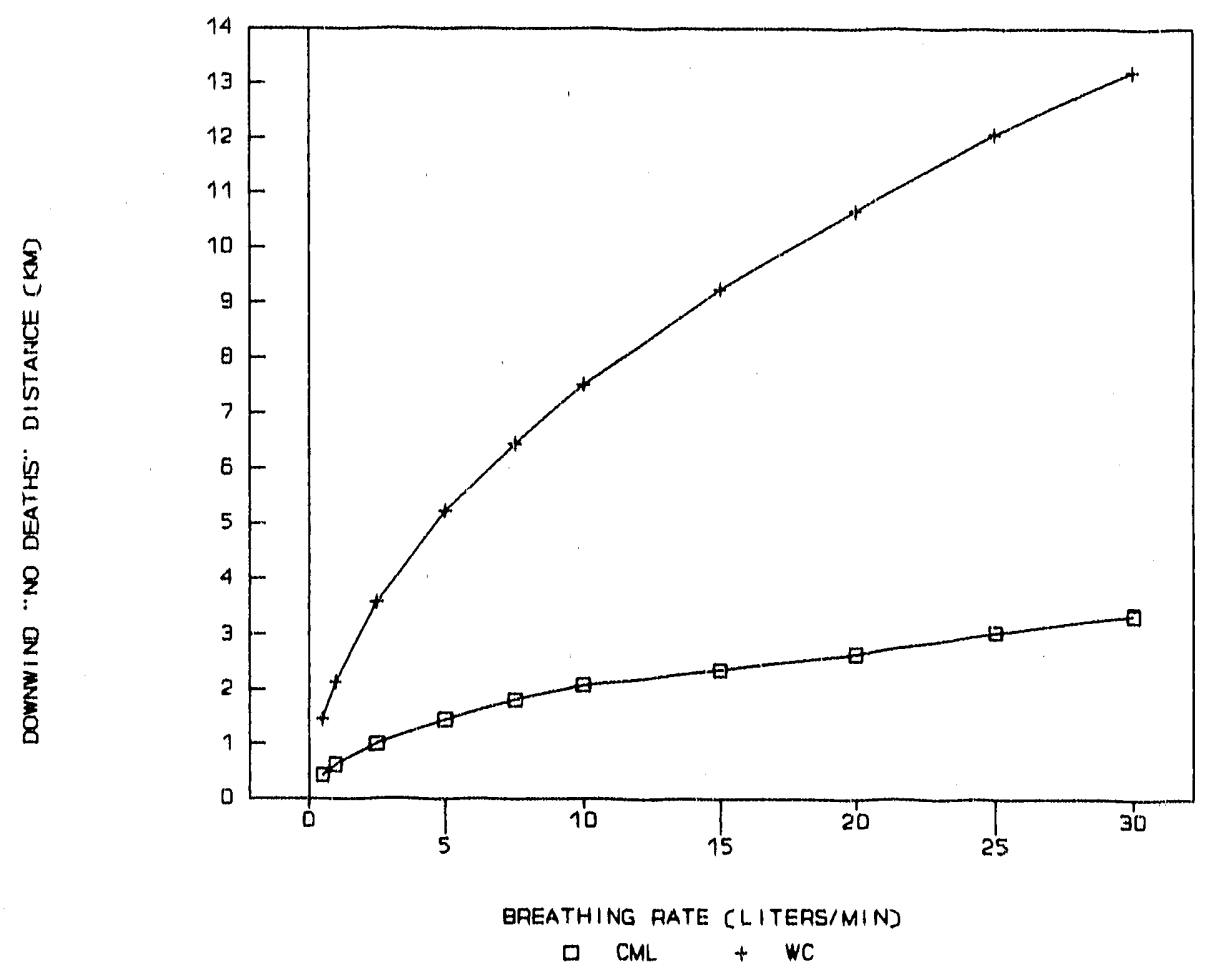

Fig. 4.30. Variable breathing rate (liters/min)-Scenario 4. 


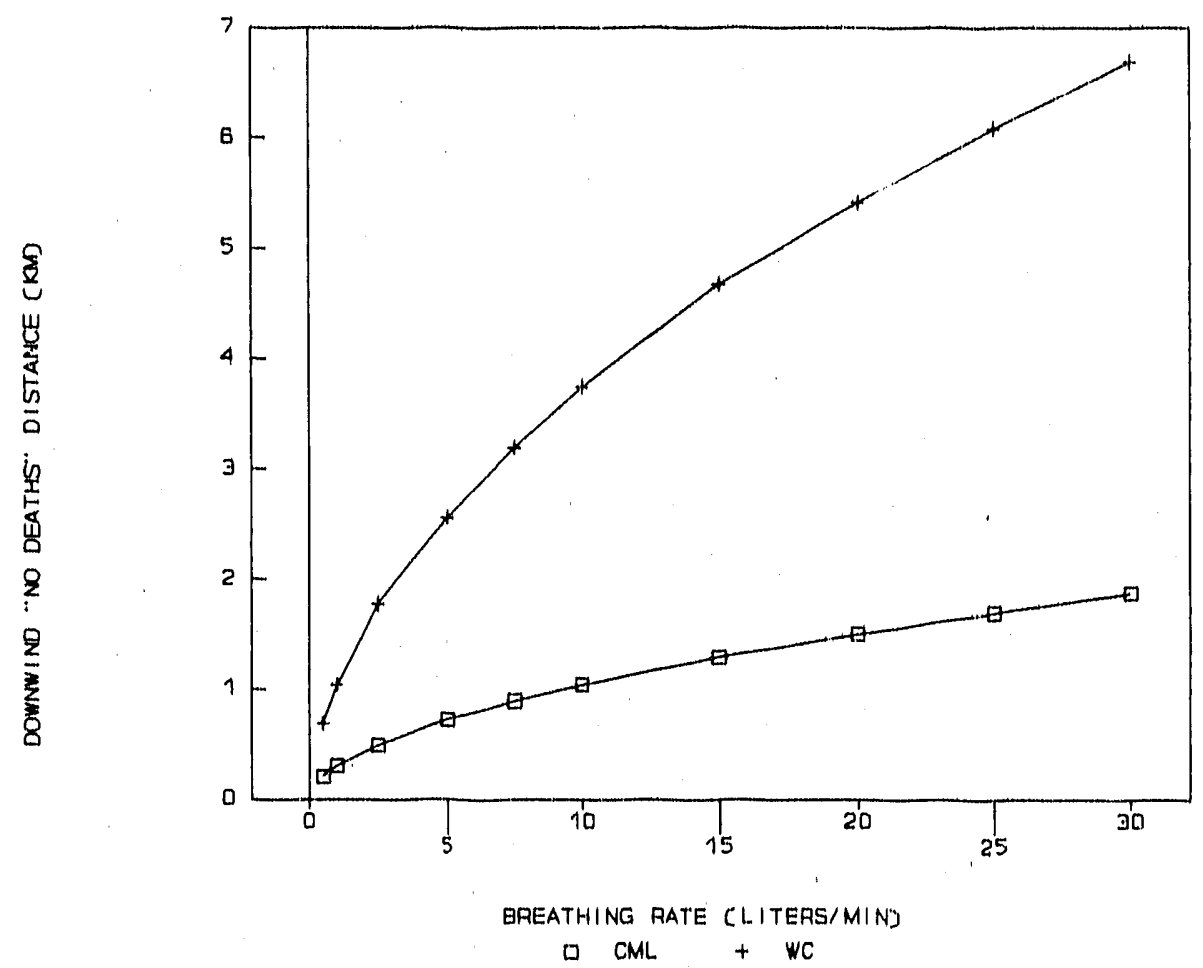

Fig. 4.31. Variable breathing rate (liters/min)-Scenario 5.

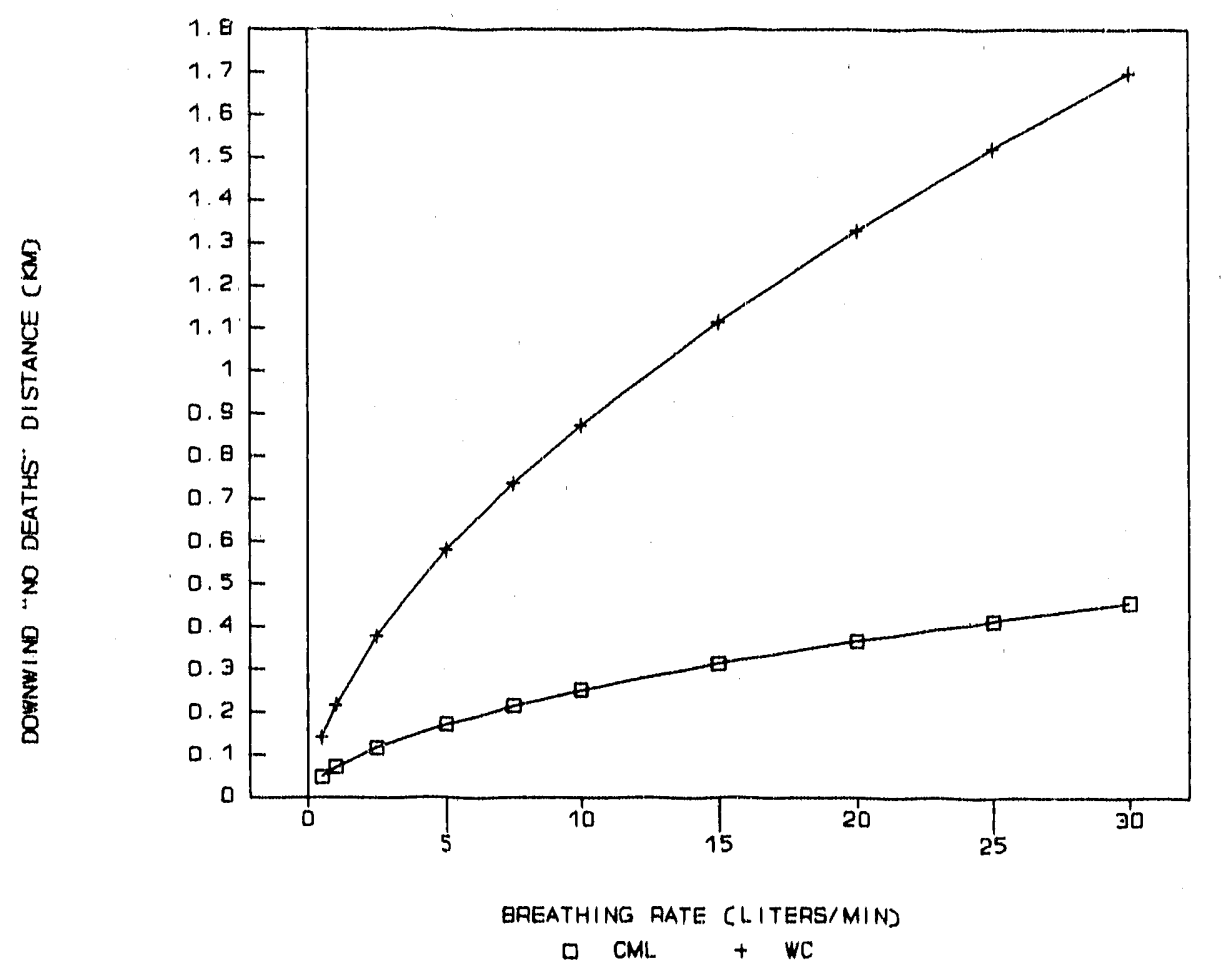

Fig. 4.32 Variable breathing rate (litera/min)-Scenario 6. 
conditions loses importance in downwind distance calculation as the breathing rate increases. WC conditions have lower sensitivity because of lower wind speed.

For all other scenarios, the sensitivity to breathing rate is high for WC conditions and low for ML conditions. Sensitivity to breathing rate increases for larger release amounts (scenarios 2 and 4 ) where a change in breathing rate of 5 liters per minute can result in a downwind "no deaths" distance difference of greater than $1 \mathrm{~km}$.

During the course of this analysis, an error was discovered in the D2PC code (M. M. Myirski, U.S. Army CP.DEC, personal communication with D. P. Lombardi, Oak Ridge National Laboratory, Oak Ricige, Tenn., May 11, 1992). For releases that involved explosive VX munitions (scenarios 1 and 2), the downwind "no deaths" distance decreased with increased breathing rate. G. L. Chen, Oak Ridge National Laboratory, identified a coding mistake in which the breathing rate component was misplaced to the percutaneous term. This error has since been corrected, and the data collected for this ani ysis were computed using the new code.

Figures 4.33 and 4.34 show the downwind distance sensitivity to a range of skin penetration factors. Skin penetration is defined for a specific type of exposure and a specific type of clothing. The default value of 0.022 is indicative of light summer clothing (Whiteacre et al. 1987, p. 44). Skin penetration factor relates the deposition dose to the intravenous dose, and selected values range from 0.001 to 0.9 . Values at the low and high end of the range are not likely; however, there is no clearly defined range of reasonable skin penetration factors. The range of values was selected to provide a complete analysis. Two plots each are shown in Figs. 4.33 and 4.34, which correspond to WC and CML meteorological conditions. For both plots, the downwind distance increases with increasing skin penetration factor values. This result is in agreement with the empirically derived inhalation-deposition equation used in D2PC.

For scenario 1, these two plots intersect one another, similar to the variable breathing rate case. This is due to the same effect discussed with the sensitivity of the breathing rate; however, the result is opposite. For low values of skin penetration factor, the breathing rate term dominates, and wind speed has smaller importance in the calculation of downwind distance; therefore, the downwind distance for WC conditions is greater than CML. As the skin factor increases, wind speed takes on increased importance, and eventually the downwind distance calculated for CML conditions exceeds WC. This crossover does not occur in scenario 2 due to the damping caused by other release modes.

There is more sensitivity to skin penetration factor with CML meteorological conditions. The percutaneous dose component is directly proportional to wind speed, and a higher wind speed associated with CML conditions allows this component to have a greater rate of increase as the skin penetration becomes larger. 


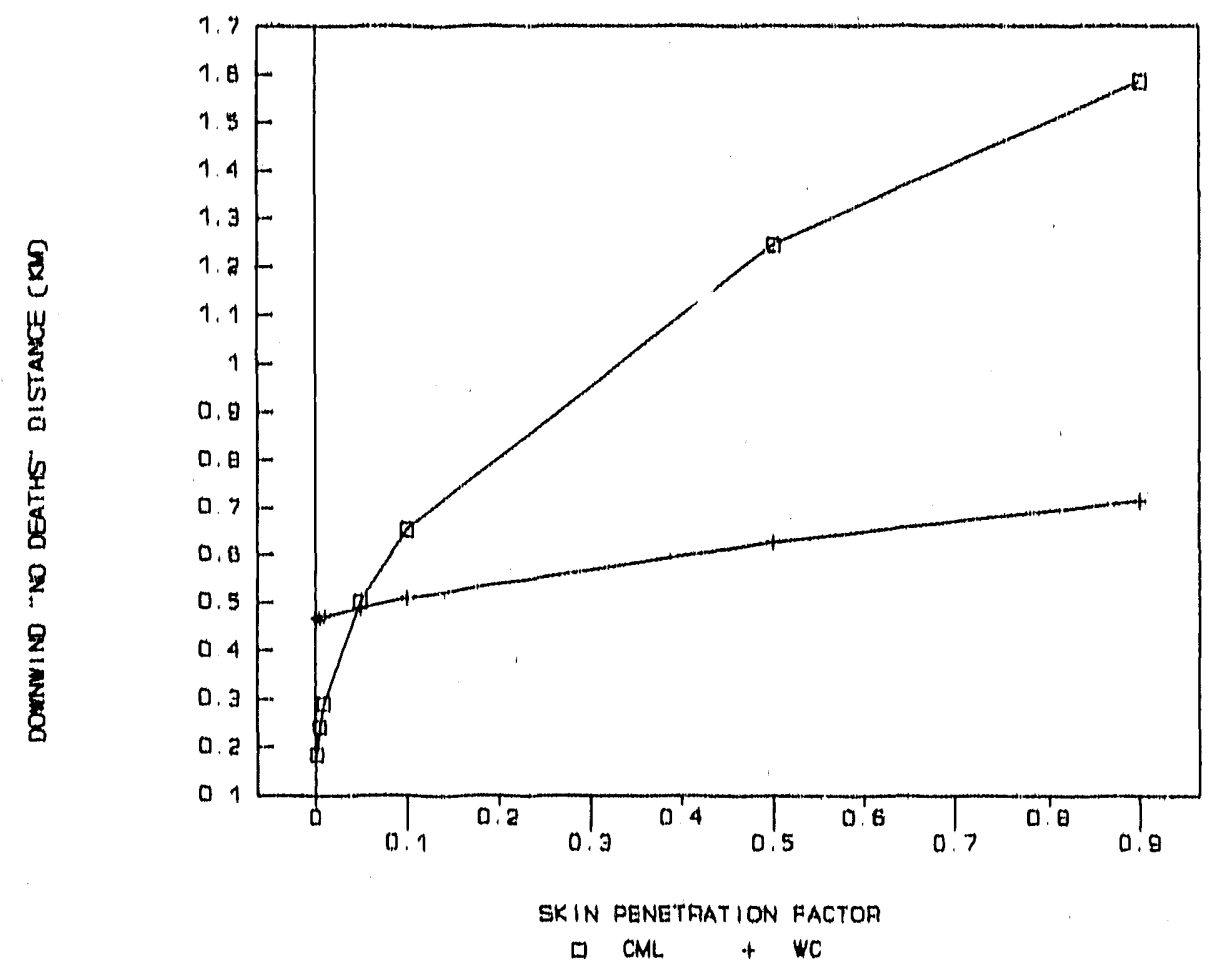

Fig. 4.33. Variable stin penetration factor-Scenario 1.

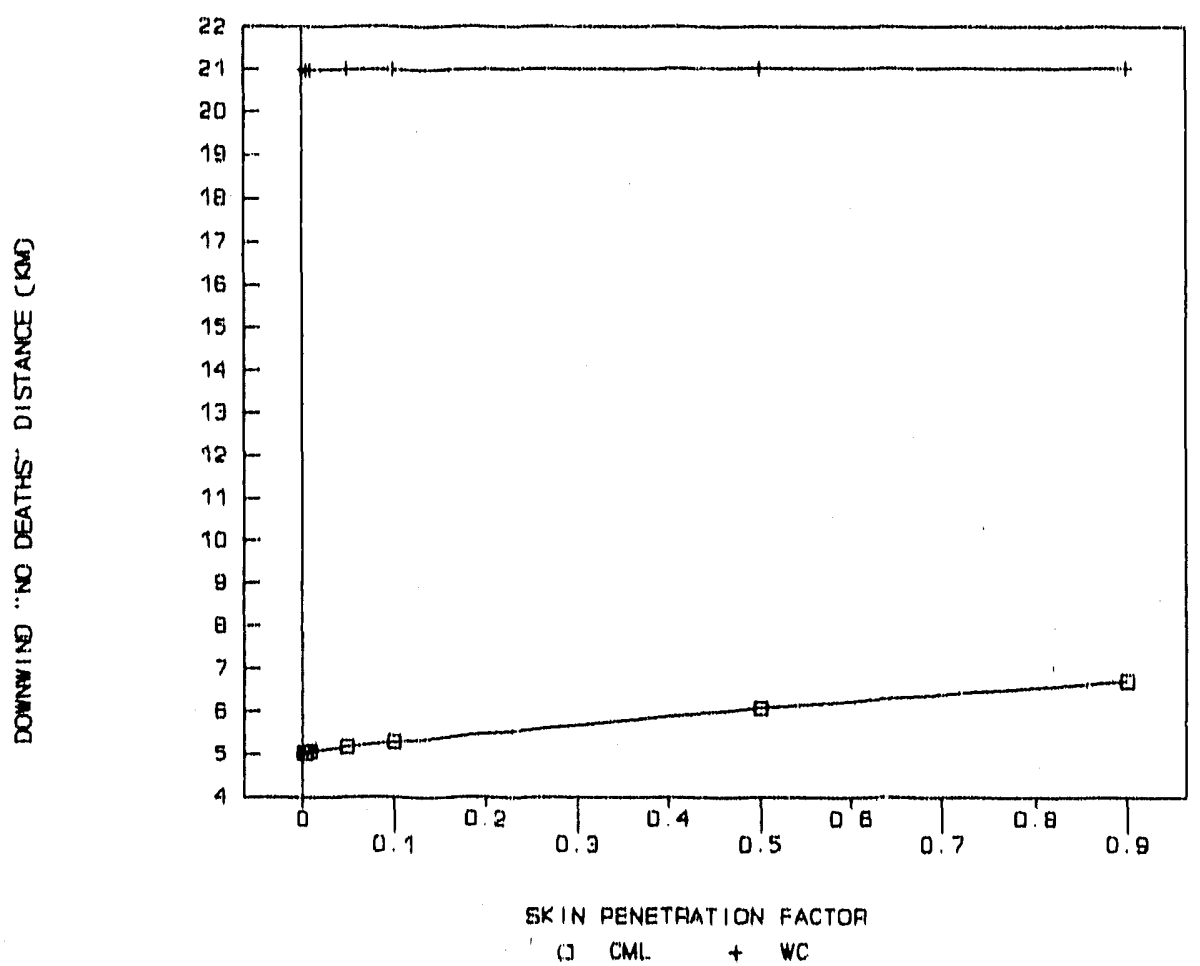

Fig. 4.34. Variable skin penetration factor-Scenario 2 


\section{SUMMARY AND CONCLUSIONS}

This sensitivity analysis focused on the ability of D2PC to provide reasonable estimates of human dose under six accidental release scenarios involving chemical agents VX, GB, and HD (sulfur mustard). 'Two categories, corresponding to conservative most likely (CML) and worst case (WC) meteorological conditions, provided the reference for standard input values. A particular input parameter was varied against these standard values. In analyzing model sensitivity to wind speed and the wind profile exponent, standard input values corresponding to $\mathrm{CML}$ and WC conditions could not be used because these parameters' values depended on stability conditions; hybrid standard input values were used (a combination of CML and WC conditions). Table 5.1 shows a qualitative sensitivity rating of each parameter relative to the other parameters. The parameters exhibiting the highest sensitivity in the calculation of downwind distance are at the top of Table 5.1. Parameters exhibiting lower sensitivity to the calculations of downwind distances are found lower in the table.

The ability of D2PC to estimate dose of interest is very sensitive to wind speed input, particularly in a stable atmosphere (stabilities $E$ and F). Model sensitivity decreases for higher wind speed values, except when the inhalation-deposition algorithm for VX (scenarios 1 and 2) is involved. D2PC dose calculations are very sensitive to mixing height input, especially when the mixing height is relatively low (around $100 \mathrm{~m}$ for all six scenarios analyzed). As mixing height increases above $100 \mathrm{~m}$, model sensitivity significantly decreases. D2PC is sensitive over a wider range of mixing heights when larger amounts of agent are released.

D2PC has little sensitivity to the input parameters involved in vapor depletion: wind profile exponent and surface roughness height. However, the model displays some sensitivity to wind profile exponent during A stability. D2PC did display a great deal of sensitivity regarding the selection of the vapor depletion module (either on or off). In the calculation of the surface deposition velocity, the effect of atmospheric turbulence is handled two different ways. In terms of stability, a more stable atmosphere (with less atmospheric turbulence) is defined by a lower generalized stability parameter. With a lower stability parameter, the calculated vapor deposition velocity is less, leading to a greater "no deaths" distance. In terms of surface roughness, the vapor deposition velocity is lower with higher surface roughness (creating more atmospheric turbulence). This leads to the calculation of a greater "no deaths" distance.

D2PC has very little sensitivity to evaporative release input paraneters, temperature and pressure. Sensitivity increases as temperature increases, but the relative sensitivity is still small. D2PC sensitivity to atmospheric pressure is minute over a wide range of surface values.

D2PC is considerably sensitive to breathing rate for instantaneous releases of VX (scenario 1) during CML conditions and for all other releases during WC conditions. Sensitivity to the skin penetration factor is also high for CML conditions for instantaneous releases of VX. During this analysis, an error in the D2PC code was discovered in which downwind distance decreased with increased breathing rate for instantaneous releases of VX. This coding error has been corrected, and the data used in this report are from the updated version of D2PC.

Values for certain parameters can be entered into the model that would not characterize a true physical process. The model may or may not adjust for this mistake. For instance, if the wind speed is $10 \mathrm{~m} / \mathrm{s}$ and stability is mistakenly input as category $B$, the resulting error is small because there is little model sensitivity to stability at higher wind 
speeds. However, if the stability is category $A$ and the wind profile exponent is mistakenly input as 0.45 , instead of a 0.10 , the resultant error in the calculation of downwind distance could be significant.

Even though the exact value of a particular input parameter may not be known, the output generated by D2PC, combined with an understanding of the model sensitivity, can lead to a reasonable estimate of a particular dose received downwind of an accidental release. Information regarding the sensitivity of D2PC output to variable input data may provide crucial information for decision makers involved in an accidental release of chemical ageni. Decision makers must know model sensitivity and limitations when interpreting the downwind distance output in order to make effective decisions regarding public safety.

Table 5.1 Qualitative sensitivity ranking of parameters

\begin{tabular}{|c|c|c|}
\hline Parameter & $\begin{array}{c}\text { Downwind } \\
\text { "no deaths" distance } \\
\text { calculation sensitivity }\end{array}$ & Remarks \\
\hline Wind speed & High & $\begin{array}{l}\text { Highest for more stable } \\
\text { atmospheric conditions and } \\
\text { lower wind speeds }\end{array}$ \\
\hline Mixing layer height & High & $\begin{array}{l}\text { Highest for CML } \\
\text { conditions and at low } \\
\text { values of mixing height }\end{array}$ \\
\hline Breathing rate & Moderate-High & $\begin{array}{l}\text { Highest for CML } \\
\text { conditions for } \\
\text { instantaneous releases of } \\
\text { VX, and WC conditions for } \\
\text { all other releases }\end{array}$ \\
\hline Skin penetration factor & Moderate-High & $\begin{array}{l}\text { Highest for CML } \\
\text { conditions }\end{array}$ \\
\hline Atmospheric stability & Low-High & $\begin{array}{l}\text { High for low wind speeds } \\
\text { and low at high wind } \\
\text { speeds }\end{array}$ \\
\hline Wind profile exponent & Low-Moderate & $\begin{array}{l}\text { Moderate for A stability } \\
\text { and low for all other } \\
\text { stabilities }\end{array}$ \\
\hline Temperature & Low-Moderate & $\begin{array}{l}\text { Moderate for higher } \\
\text { temperature values }\end{array}$ \\
\hline Surface roughness & Low-Moderate & $\begin{array}{l}\text { Moderate with lowest } \\
\text { surface roughness values }\end{array}$ \\
\hline Atmospheric pressure & Low & Low over entire range \\
\hline
\end{tabular}




\section{REFERENCES}

EPA (Environmental Protection Agency) 1986. Guideline on Air Quality Models (Revised), EPA-450/2-78-027R, Office of Air Qualitity Planning and Standarcls, Research Triangle Park, N.C.

Gifford, F. A., Jr. 1968. "An Outline of Theories of Diffusion in the Loiver Layers of the Atmosphere," pp. 66-116 in Meteorology and Atomic Energy-1968, ed. D.H. Slade, USAEC Report TID-24190, U.S. Atomic Energy Commission, NTIS.

Miller, R. L. and F. C. Kornegay 1989. "Downwind Doses from Potential Releases Associated with the Chemical Stockpile Disposal Program," pp. 31.5-323 in The Environmental Professional 2(4).

Munro, N. B., al. 1990. "Treating Exposure to Chemical Warfare Agents: Implications for Health Care Providers and Community Emergency Planning," pp. 205-215 in Environmental Health Perspectives Vol. 89.

Pasquill, F. 1960. "The Estimation of the Dispersion of Windborne Material," pp. 33-49 in The Meteorological Magazine, Vol. 90, No. 1,063.

Pasquill, F. 1974. Atmospheric Diffusion, Second Edition, John Wiley \& Sons, New York.

Snyder, W. S., et al. 1974. "Report of the Task Group on Reference Man," International Commission on Radiological Protection No. 23, Pergamon Press, New York.

Solomon, I., M.D., et al. 1970. "Methods of Estimating Hazard Distances for Accidents Involving Chemical Agents (U)." ORG Report 40, U.S. Army Munitionis Command Operations Research Group, Edgewood Arsenal, Md.

Sutton, O. G. 1932. "A Theory of Eddy Diffusion in the Atmosphere," p. 143 in Proc. $R$. Soc. Ser. A 135, London.

Sutton, O. G. 1953. Micrometeorology, McGraw Hill Book Company, Inc., New York.

U.S. Department of the Army 1988. Chemical Stockpile Disposal Program Final Programumatic Environmental Impact Statement Vol. 1, Program Executive Officer, Program Manager for Chemical Demilitarization, Aberdeen Proving Grcund, Md.

Whiteacre, G. C., et al. 1987. Personal Computer Program for Chemical Hazaral Prediction (D2PC), U.S. Army Chemical Research and Development Center, Aberdeen Proving Ground, Md. 


\section{INTERNAL DISTRIBUTION}

\author{
1. M. V. Adler \\ 2. T. J. Blasing \\ 3. Central Research Library \\ 4. G. L. Chen \\ 5. Document Reference Section \\ 6. K. S. Gant \\ 7. P. S. Gillis \\ 8. G. W. Kerley \\ 9-11. Laboratory Records \\ 12. Laboratory Records-RC \\ 13. M. A. Linn
}
14-38.
D. P. Lombardi
39.
R. L. Miller
40.
M. D. Morris
41. W. N. Naegeli
42. ORNL Patent Office
43. R. M. Reed
$44 . \quad$ R. B. Shelton
45-54. J. H. Sorensen
55.
B. M. Vogt
56.
A. P. Watson
57.

\section{EXTERNAL DISTRIBUTION}

58-72. K. Blackman, Federal Emergency Management Agency, 500 C Street, SW, Washington, DC, 20472

73-97. D. Fisher, U.S. Department of the Army, Office of the Assistant Secretary, Installations, Logistics, and Environment, The Pentagon, Washington, DC, 20310

98. M. Myirski, U.S. Department of the Army, Chemical Research, Development and Engineering Center, SMCCR-OPA, Aberdeen Proving Ground, MD, 21010

99. Office of Assistant Manager for Energy Research and Development, Oak Ridge Operations, P.O. Box 2001, U.S. Department of Energy, Oak Ridge, TN 378318600

100-109. Office of Scientific and Technical Information, P.O. Box 62, Oak Ridge, TN 37831 

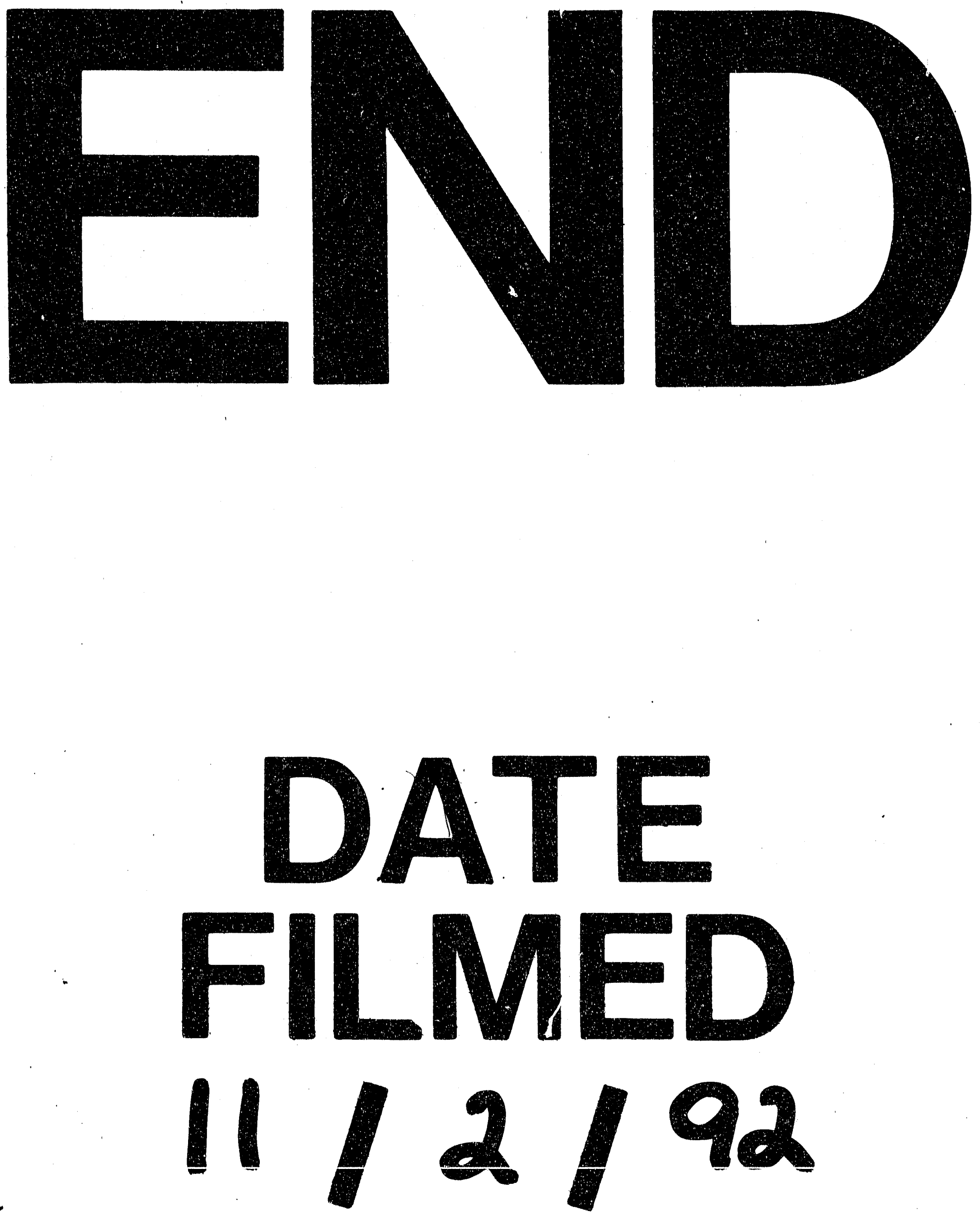

事 
